\title{
CAMBIOS EN LA VITICULTURA DE ANDALUCIA ORIENTAL DURANTE LA CRISIS DE FINALES DEL SIGLO XIX. ESTUDIO SOBRE LOS DATOS DE LOS INFORMES CONSULARES BRITANICOS
}

JOSE MORILLA CRITZ

Universidad de Alcalá de Henares

\section{INTRODUCCION}

Lo más destacado de la historiografía agraria española reciente es, tal vez, que se han empezado a superar las graves limitaciones que existían para un análisis riguroso de la dinámica del sector al haberse empezado a aportar, sobre todo por el GHR (Grupo de Historia Rural), una serie de estados sobre la producción y las superficies cultivadas, deducidos de fuentes oficiales empleadas críticamente. Esto último ha permitido realizar importantes trabajos sobre rendimientos y evolución del producto agrario, entre el último cuarto del siglo $\mathrm{xIx}$ y el segundo decenio del $\mathrm{xx}^{1}$.

Con un panorama de información notablemente mejor que el de hace diez años, se ha podido avanzar claramente en la cronología, catalogación y explicación de los problemas del sector agrario español, al menos en opinión de algunos de los más destacados investigadores del tema, como Garrabou y Sanz Fernández ${ }^{2}$. Uno de los problemas en los que más se ha profundizado es el de la llamada «crisis finisecular», iniciada a mediados de los años setenta del siglo XIX.

No obstante, y esto vale para la investigación sobre toda la segunda mitad del siglo $\mathrm{xIx}$ y el primer tercio del $\mathrm{xx}$, hemos de reconocer que no estamos ante datos estadísticos incontestados. Se duda a veces incluso de que las fuentes oficiales sean, en todos los casos, el mejor camino para conocer adecuadamente la producción y los rendimientos ${ }^{3}$. Por ello creemos que hay que incrementar, sobre todo para momentos anteriores a 1890 , la investigación en fuentes alternativas, aunque sólo sea como medio de contrastar la información oficial disponible.

' Grupo de Historia Rural (1979), pp. 129.173; (1980); (1981 a); (1981 b); (1983), pp. 185-252, y (1985), pp. 52-70; J. Sanz Fernández (1981), pp. 303-330; (1985 a), pp. 265 . 310, y (1985 b), pp. 193-278; R. Garrabou y J. Sanz (1985); J. Zambrana (1987).

2 R. Garrabou y J. Sanz (1985), pp. 186-187.

A. M. Bernal (1985 a), pp. 216-229; J. Maluquer (1987), pp. 74-75. 
Por otra parte, por lo que respecta a Andalucía, la labor orientada a conocer estadísticamente la evolución de su agricultura y, en particular, los efectos de la «Gran depresión» de 1873-1896, ha sido escasa hasta muy recientemente. De esta manera tenemos muy poco conocimiento de superficies cultivadas, producción, técnicas, productividad, rentas, salarios, beneficios, inversión y comercialización de los productos, a pesar de la abundante historiografía que existe sobre la agricultura andaluza en todos los tiempos ${ }^{4}$.

El trabajo más amplio del sector primario de Andalucía Oriental en esa época es el estudio de Jiménez Blanco ${ }^{5}$. Aparte de otras consideraciones que sobre esta obra hemos hecho en un reciente comentario ${ }^{6}$, es de destacar que, por lo que respecta a la crisis señalada, la investigación de Jiménez Blanco confirma, a mi entender, una hipótesis anteriormente formulada por Bernal y Drain de que «no hubo una crisis, sino varias, de etiología diversa y duración también diferentes»?

De entre las diversas crisis particulares a las que se vio sometida la agricultura andaluza de entonces, la de la viticultura de las provincias marítimas orientales, tal vez fue la de consecuencias económicas y sociales más profundas a corto y medio plazo o, por lo menos, así se ha considerado por algunos estudiosos del tema ${ }^{8}$. Por otra parte, es notable el grado de disenso que hay entre diversos investigadores al tratar de las causas determinantes de aquella crisis ${ }^{9}$. Tiene interés, por tanto, que intentemos aportar fuentes alternativas a las utilizadas hasta ahora, para conocer lo que ocurrió en esa parcela de la agricultura de Andalucía Oriental, las valoremos y planteemos algunas explicaciones, a veces hipótesis, sobre la dinámica de la misma.

- Exceptuando, por ahora, los trabajos referidos expresamente a la viticultura de An dalucía Oriental, algunos problemas del sector primario andaluz a finales del xIX relacionados con el crecimiento son tratados en las obras siguientes: A. M. Bernal y $M$. Drain (1975), (1981), pp. 71-83, y (1985a); A. M. Bernal (1985a), pp. 215-263, y (1985 b), pp. 281-297; F. Herán (1981): M. Martín Rodríguez (1982); $G$. Núñez Romero-Balmas (1983), pp. 1195-1214; G. Méndez González y A. Sánchez Picón (1985), pp. 167-178; A. Gámez Amián (1985), pp. 149-166; J. S. Gutiérrez Alvarez y E. Ruiz de Azúa (1985), pp. 67-75; Clara E. Núñez Romero-Balmas (1985); J. Simpson (1985), pp. 166-191; J. I. Jiménez Blanco (1986).

3 J. I. Jiménez Blanco (1986 y 1985).

- J. Morilla Critz (1988 b).

7 A. M. Bernal y M. Drain (1985a), p. 438.

- J. A. Lacomba (1974), pp. 128-134, y (1986), p. XV.

9 Véanse, al respecto, M. T. Carnero (1980), pp. 129-133; J. Morilla Critz (1974), pp. 85-87; J. Guisado (1983), pp. 179.184; E. Diego García y M. ${ }^{\circ}$ T. Solano Sobrado (1985), p. 124; C. Pellejero (1986), p. 580; J. I. Jiménez Blanco (1986), pp. 634-643. 


\section{FUENTES}

El trabajo que sigue se basa, aparte de en lo conocido sobre el sector gracias a las aportaciones de otros investigadores, fundamentalmente en lo reflejado cuantitativa y cualitativamente en los «Informes Comerciales de los Cónsules, Vicecónsules y Agentes Consulares británicos» para diversas poblaciones de Andalucía Oriental, e incorporamos, también, la información de un trabajo propio de 1974, que procedía, básicamente, de la prensa mercantil de Málaga ${ }^{10}$.

Con respecto a la documentación consular británica, no es necesario extenderse mucho para explicar las posibilidades de información que ofrece y su fiabilidad, muy especialmente para la investigación histórico-económica de Andalucía en el siglo xIX. El trabajo pionero de identificación de Nicolás Sánchez-Albornoz en $1967^{11}$, el de catalogación de Gómez Mendoza ${ }^{12}$ y la utilización para investigaciones concretas de Nadal Farreras ${ }^{13}$, Simpson ${ }^{14} \mathrm{y}$, sobre todo, de Clara Eugenia Núñez ${ }^{15}$, nos han acercado al conocimiento crítico de esta fuente

En particular, para el establecimiento de las cifras de exportación de los diferentes productos vitícolas de Andalucía, los Informes Consulares Británicos (ICB) pueden ser más útiles que los registros oficiales de Comercio Exterior y de Cabotaje: entre 1865 y 1913 la información de aquéllos es más homogénea, ya que siempre aparecen desagregados los datos de cada esquilmo y separados de los conjuntos generales de frutos secos y frescos, cosa que frecuentemente no ocurre con los registros oficiales, en los que, además, no hay el mismo criterio en las clasificaciones de los comercios exterior $y$ de cabotaje.

En cuanto a las cifras, es conocida la estimación por defecto de los datos oficiales. El que las de los Informes Consulares se sitúen, normalmente, por encima de aquéllas, aceptando las consideraciones de Clara Eugenia Núñez ${ }^{16}$ sobre el cuidadoso trabajo de los cónsules, nos hace pensar que los datos de los ICB se acercaron más a la realidad del tráfico ${ }^{17}$ que las estadísticas oficiales.

${ }^{10} \mathrm{~J}$. Morilla Critz (1974), pp. 68-89.

N. Sánchez-Albornoz (1967).

A. Gómez Mendoza (1983), pp. 89-96.

3 J. Nadal Farreras (1978).

14 J. Simpson (1985).

"Clara E. Núñez Romero-Balmas (1983 y 1985).

'Clara E. Núñez Romero-Balmas (1985), p. 37.

12 Las cifras de los ICB están, normalmente, por encima de las de la Estadística de Comercio Exterior y de Cabotaie. En un caso que hemos podido comprobar la pasa de Málaga) los ICB incluyen habitualmente no sólo las cantidades expedidas por mar, sino también las que salen para el interior. Por tante son meiores para el conocimiento real del flujo exportador y su utilización como método indirecte del cálcule de da oroducción. 
Disponer de datos de exportación más fiables permite hacer cálculos más ajustados de la producción cuando ésta ha de reconstruirse por métodos indirectos. A ello pueden ayudarnos las citras de lós $\mathrm{ICB}^{-}, \overline{y a}$ que las èstimaciones de los Ingenieros Agrónomos muestran, a nuestro entender y para algunos lugares de la subregión, una gran deficiencia por subestimación. No se explicaría de otro modo, por ejemplo, que año tras año las cifras de producción de uva en Almería fueran tan notablemente inferiores a las del volumen de exportación (derive la información de la Estadística de Comercio Exterior o de los ICB), como muestra el cuadro 1.

La diferencia se da en todos y cada uno de los años del período comparable (1898-1913), y el alejamiento de la realidad de las estimaciones de los Ingenieros queda aún más patente si tenemos en cuenta que las cifras de exportación se refieren tan sólo al puerto de Almería y no a otros de la provincia ${ }^{18}$.

\section{CUADRO 1}

Producción y exportación uva de Almería (Tms.)

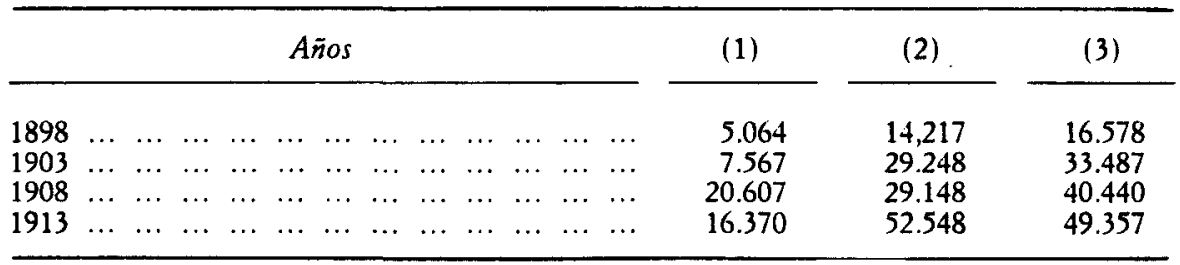

Notas: (1) Estimación oficial de la producción.

(2) Exportación según la Estadística de Comercio Exlctior.

(3) Exportación según ICB.

\section{ALGUNAS CAUTELAS EN LA INTERPRETACION DE LAS CIFRAS}

Antes de entrar a analizar los datos físicos de exportación de los productos vitícolas y la relación de aquélla con la producción de la subregión,

18 No hay, por otra parte, constancia de que por Almería se exportara uva de alguna otra provincia. Tal hecho hubiera estado reflejado en las importaciones de cabotaje, cosa que no ocurre en ningún caso. Las llegadas por tierra eran impensables, dada la ubicación de las otras zonas uveras (muy pequeñas, por cierto) de las provincias limítrofes (Granada y Murcia), perfectamente conectadas con el exterior por sus respectivos puertos marítimos, por los que salía su producción uvera. Por otra parte, los datos que poseemos desde que Almería estuvo conectada por ferrocarril con el interior demuestran que sólo había tráfico de uvas en sentido ascendente. 
conviene tener en cuenta que una de las características peculiares del estudio

de la viticultura de Andalucía Oriental es que, al menos para la época, no se puede u'tuzar un productó basicó (qué suele sèr el vino en la mayor parte de los casos) como indicador de la dinámica del sector. Hemos de enfrentarnos, por el contrario, a tres productos muy diferentes: pasas, uvas de mesa y vino, cuyo peso relativo en el conjunto vitícola varió, además. durante el período analizado precisamente, como se observa en el cuadro 2:

\section{CUADRO 2}

Distribución de los productos vitícolas

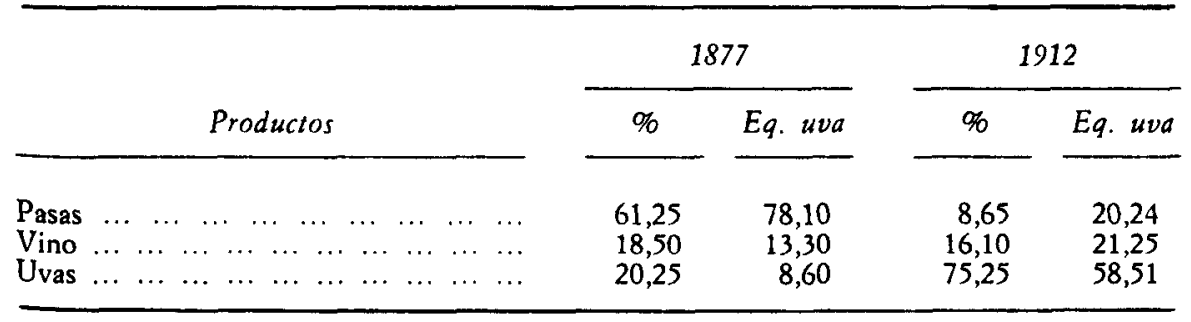

Notas: \%: porcentaje del volumen de exportación de cada producto sobre el total de productos viticolas.

Eq. uva: equivalencia en uva de los diferentes productos (pasas $\times 3$, vino $\times 1,7$ ).

FUENTES: ICB.

Por otra parte, como veremos más adelante, una interpretación de las cifras de exportación de la pasa de Málaga y de la uva de embarque de Almería y Málaga ha de ser, en su relación con la producción de estos esquilmos en la zona, muy diferente a la de las cifras de exportación del vino. Las primeras corresponden siempre a productos vitícolas procedentes de las provincias respectivas (la compra de pasa por Málaga, procedente de otros lugares, fue siempre una cosa anecdótica y cuantitativamente despreciable); sin embargo, el vino expedido desde el puerto de Málaga, único importante para este producto en la subregión, no siempre era de la provincia, ni producido con mostos de la misma o de Andalucía Oriental, incluso refiriéndonos al que aparezca con el nombre específico de «vino de Málaga».

A pesar de todo, y con estas cautelas, si lo que pretendemos es analizar la suerte que siguió el sector vitícola en su conjunto en el período de la crisis, e indagar las razones del comportamiento de los diferentes agentes durante la misma, puede ser útil considerar, en principio, que, como indica 
el gráfico 1, las distintas ramas del sector vitícola como negocios de exportación de los puertos andaluces orientales, ofrecieron perspectivas muy dife-

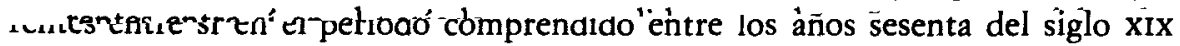
y la Primera Guerra Mundial y, también, que el periodo «filoxérico» (18781909) no significó lo mismo para las actividades de las dos zonas vitícolamente más importantes en la subregión.

\section{GRAFICO 1}

Tendencias de la exportación de los productos vitícolas de Andalucía Oriental ( $A O R$ )

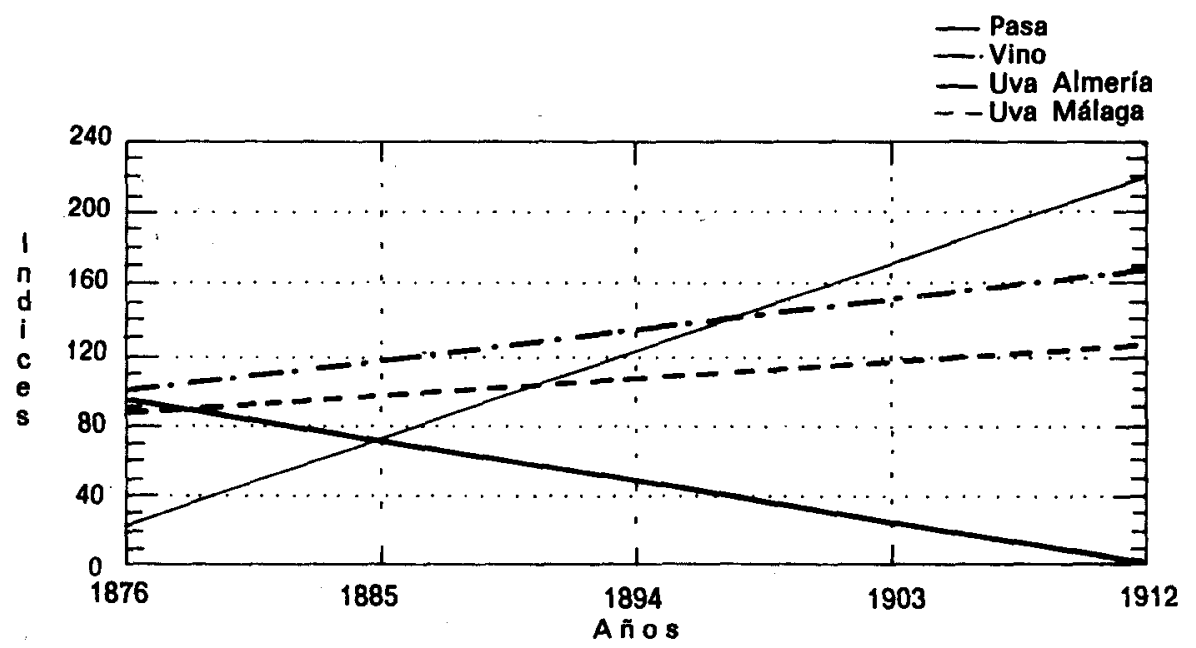

4. EVOLUCION DISPAR DE LOS SECTORES VITICOLAS: PASAS, UVAS, VINO

\subsection{Crisis del sector pasero malagueño}

La exportación de pasa de Málaga, que constituía el principal producto vitícola de la subregión antes de 1880 , sufrió una profunda crisis desde 1872 que, entre 1876 y 1899, fue acompañada también por la caída de la producción (cuadros 1 y 2 del Apéndice estadístico). La crisis en la exportación de este esquilmo comenzó antes de que la filoxera hiciera su aparición 
en la zona -1878 - . Por otra parte, es interesante considerar que la cronología de esta crisis, manifestada también en los precios (cuadro 10 del Apéndice estadístico), coincidió enteramente con la que sufrieron en los mercados internacionales los principales productos primarios europeos que vieron aparecer competidores en zonas nuevas del mundo.

Esta coincidencia corrobora, a nuestro entender, lo que afirmábamos en 1974 sobre la vinculación de la crisis pasera en Málaga a la pérdida para el sector del mercado de Estados Unidos ${ }^{19}$. Apoyando esta tesis, los testimonios de los Cónsules Bidwell y Finn nos muestran con claridad que el peligro de la competencia californiana era comprendido en los años ochenta, así como valorada correctamente la dificultad de enfrentarse a ella ${ }^{20}$.

Jiménez Blanco ha insertado la crisis pasera malagueña en un marco más genérico, pues, según él, la filoxera sorprendió a la zona en un momento en el que competían con ella y por los mismos mercados las pasas de Esmirna, Corinto y Denia, uniéndose progresivamente a esa competencia California. En esas circunstancias, el elemento decisorio que desequilibraría la situación contra la pasa andaluza sería la discriminación arancelaria de la que fue objeto, frente a las demás, en Estados Unidos ${ }^{21}$.

A nuestro entender, la explicación no puede plantearse de forma tan genérica, pues Juan Piqueras ha demostrado ${ }^{22}$ que, en el comercio pasero del siglo $\mathrm{XIX}$, nos encontramos con un mercado segmentado, con variedades que tenían destinos finales diferentes, siendo la pasa de Málaga, tanto en Gran Bretaña como en Estados Unidos, utilizada casi en exclusiva directamente para postre. Un ejemplo de que nos encontramos ante productos diferentes es el de las cotizaciones de cada variedad. En los mercados de Cette y Marsella, y por lo que respecta a las pasas de Málaga y Denia, los precios en 1891 y 1903, recogidos cada dos meses y traducidos a medidas equivalentes (francos/caja de una arroba), fueron los del cuadro 3.

19 J. Morilla Critz (1974), p. 79.

20 «El reciente cultivo extensivo de pasas en los distritos del Sur de Califarnia ha afectado ya a la demanda desde Estados Unidos de este importante género de la provincia de Málaga, y es probable eventualmente que tenga un considerable efecto en este mercadow (Bidwell: 1886 LXV, p. 489). «Las pasas de California, aunque inferiores en calidad a la moscatel de Málaga pueden ser producidas a un coste tan barato como para casi excluir a la última de los mercados del Norte de Américas (Finn: 1889 LXXX, p. 546). "El actual nivel de derechos de importación no -se precisa como protección, puesto que las pasas de California son mucho más baratas en Estados Unidos que las pasas españolas. Siendo éste el caso debe esperarse una reducción aún más amplia» (Finn: 1889 LXXX, p. 550). «La oferta actual parece suficiente para la demanda, por cuanto anteriormente los Estados Unidos eran un consumidor de la mitad de la cosecha, es decir un millón de cajas, esta campaña se han enviado no mucho más de cien mil: un auténtico hundimiento (Finn: 1890-91 LXXXVII, p. 777).

${ }_{22}^{21}$ J. I. Jiménez Blanco (1986), pp. 588-589.

22 J. Piqueras (1985), pp. 59-60. 


\section{CUADRO 3}

Precios de las variedades de pasa de Málaga y Denia en los mercados de Cette y Marsella

\begin{tabular}{|c|c|c|c|}
\hline \multicolumn{2}{|c|}{1891} & \multicolumn{2}{|c|}{1903} \\
\hline Pasa Málaga & Pasa Denia & Pasa Málaga & Pasa Denia \\
\hline $\begin{array}{c}8,5 \\
10,0 \\
10,0 \\
10,0 \\
10,0-12,0 \\
10,0-12,0\end{array}$ & $\begin{array}{l}5,5-5,6 \\
5,5-5,6 \\
5,5-5,6 \\
5,5-5,6 \\
5,5-5,6 \\
5,0-5,6\end{array}$ & $\begin{array}{l}8,0-12,0 \\
9,0-12,0 \\
9,0-13,0 \\
9,0-12,0 \\
9,0-12,0 \\
9,0-14,0\end{array}$ & $\begin{array}{l}7,5-8,0 \\
5,0-6,0 \\
7,5-8,0 \\
7,5-8,0 \\
7,5-8,0 \\
7,0-7,2\end{array}$ \\
\hline
\end{tabular}

Fuentes: 1891, Boletin Semanal de Estadistica y Mercados; 1903, Boletin de Comercio $e$ Información Agricola y Estadística de Mercados, Archivo del Ministerio de Agricultura.

Las diferencias de los precios son tales y tan estables porque corresponden, lógicamente, a productos diversos. Por ello, parece más lógico ligar las dificultades de comercialización de las variedades malagueñas a razones que tengan que ver con cambios en las modas, los gustos y los sistemas alimenticios de aquellos lugares, anteriormente grandes consumidores de ese artículo de postre y, también, a la aparición de competidores de sus mismas características con una más favorable estructura de costes.

En el cuadro 7 del Apéndice estadístico mostramos la evolución de la exportación de pasa malagueña, desagregada por mercados de destino. En el mismo se puede observar cómo, desde comienzos de los años setenta del siglo xIx, sus mercados se reducían progresivamente. Aunque algunos de ellos estuvieran en ascenso hasta 1876 (Estados Unidos, Francia, Norte de Europa, Mediterráneo, América del Sur y el interior), desde 1872 sus ganancias no compensaban las pérdidas en los de Gran Bretaña y las colonias británicas. Después, entre 1876 y 1879 , ya todos los mercados se redujeron conjuntamente, apareciendo desde entonces la evolución del mercado de Estados Unidos como determinante del futuro de esta rama de la viticultura de Andalucía Oriental. Pero en ese mercado, como demostramos hace tiempo, a partir de esos años precisamente la producción californiana empezaba a lanzar al mercado de Estados Unidos el producto que competía ventajosamente con el de Málaga, sin que fuera precisa tan siquiera la protección arancelaria.

La profunda crisis de este sector de la viticultura andaluza fue, pues, 
una de las manifestaciones del impacto del desarrollo de la agricultura ultramarina sobre el tradicional sistema productivo del área mediterránea. En este caso concreto, las explotaciones californianas eran capaces de producir desde los años setenta del siglo XIX a unos costes tan bajos que, en unión de una demanda muy elástica, como corresponde a un bien no de primera necesidad y en regresión tal vez por un cambio en los hábitos de consumo, convirtió en marginales a corto plazo a una porción de viticultores paseros de Andalucía Oriental.

Finalmente, consideramos interesante incorporar a la discusión sobre las causas de la crisis del negocio pasero de la zona las consecuencias que para la comercialización de este artículo pudieran haber tenido los cambios habidos por entonces en la tecnología naval, por dos razones:

1. La posibilidad de plantearse la sustitución de parte del consumo de «frutos secados» del Mediterráneo por frutos frescos en los países de destino, al contarse con buques más rápidos desde que hubo navegación a vapor y sistemas de preservación adecuados ${ }^{23}$.

2. El cambio de estructura de los negocios exportadores en la zona cuando aparecieron las grandes compañías de vapores que, ajenas a las tradicionales relaciones en las que los asentadores y grandes fletadores autóctonos asumían los riesgos financieros de las operaciones, tomaban ahora solamente fruto en consignación, trasladando directamente los riesgos del mercado a los viticultores ${ }^{24}$.

En todo caso, y esto es lo sustancial para este trabajo, lo que hoy estamos en condición de afirmar es que los problemas de este gran capítulo de la

${ }^{23}$ Como se sabe, desde los años sesenta del siglo xIx los buques a vapor comienzan a hacer su aparición, llegando a dominar el tráfico ya en los años setenta, y, junto a ello, también se transforman los sistemas de preservación de las mercancías, apareciendo incluso los buques frigoríficos. En el transporte de frutos del Mediterráneo español, los vapores empezaron a utilizarse en los años setenta (J. Piqueras 1985 p. 109, y Cónsul Bidwell: Replies to Queries.... p. 320). Por la misma época, el embalaje de los frutos delicados - como la uva- se perfeccionó con la incorporación, por ejemplo de la viruta de corcho, que al no dañar al fruto y mantenerto en un ambiente completamente seco facilitaba su conservación (I. I. Tíménez Blanco, 1986, pp. 604-605, y Cóńsul'Wilkínsoñ 1878-79 LXX, p. 572).

${ }^{24}$ Según el Cónsul Bidwell, «hacia 1870 los négocios estaban prácticamente en manos de unas pocas grandes casas, por medio de las cuales eran embarcados el total de tos car: gamentos mientras que desde entonces el comercio se ha dividido entre muchos embarcadores algunos sin capital, incapacitados para pagar por el fruto embarcadó en Tetràs libradas contra conocimientos de embarque, y la competencia del comercio ha conducido naturalmente a ajustados precios y a la disminución de beneficios" (Bidwell: Replies to Queries..., p. 320). Ciertamente, era una situación similar a la planteada en otros puertos del Sur y el Levante español por los que se expedían frutos y vinos, como han estudiado J. Simpson (1985), pp. 186-187, y J. Piqueras (1985), pp. 108-112. 
viticultura de Andalucía Oriental se originaron en los mercados internacionales antes de que la filoxera devastara los campos $\mathrm{y}$, también, que los problemas de esos mercados se agudizaron paralelamente a la plaga.

\subsection{Expansión en el sector uvero}

Las cifras de exportación de la uva en fresco de Andalucía Oriental (las modestas cantidades de Málaga y los grandes embarques de Almería) indican, según los cuadros 3 y 4 del Apéndice estadístico, que en este sector, a pesar de estar expuesto a la crisis filoxérica como el resto de la viticultura, se vivió, entre 1875 y 1914 , una expansión extraordinaria.

Esta rama de la viticultura, pues, constituyó en la zona el paradigma opuesto al de la «crisis vitícola» que se vincula al desarrollo del mal filoxérico. En este caso hubo, tanto en Málaga como en Almería, una decidida acción contra la filoxera por parte de los viticultodes uveros, dentro de un proceso general de expansión en el que replantar cepas fue casi una pequeña anécdota.

La lucha contra la filoxera en este sector pudo contar con la ventaja de conocerse ya los ensayos frustrados y de éxito de las zonas paseras y vitivinícolas, pues, como se sabe, el insecto transmisor de la plaga se expandía en círculos concéntricos y las zonas más aptas para la fructificación de las variedades parraleras se encontraban al Este (provincia de Almería en general) y al Oeste (margen derecho de la Hoya de Málaga) del núcleo inicial de la plaga, pero no cabe duda que el elemento explicativo principal del boom exportador uvero, que arrastró a la producción, se encuentra en las favorables expectativas que este esquilmo encontraba en los mercados exteriores, al contrario de lo que le ocurría al sector pasero ${ }^{25}$.

Es interesante destacar que, como indican los cuadros 8 y 9 del Apéndice estadístico, la exportación de la uva de embarque crecía, sobre todo, por la ampliación del mercado de Estados Unidos, cuya pérdida era la causa princi-

${ }^{25}$ Durante los peores momentos para el negocio pasero (1873-1896) fue cuando se dieron, precisamente, las mejores expectativas para la uva de embarque. Ello se reflejaba en los elevados precios que el fruto alcanzaba en tales años (véase cuadro 11 del Apéndice estadístico). En tales circunstancias, como reflejaba el Cónsul Wilkinsan, de Málaga, hasta los cosecheros de uva moscatel - tradicionalmente dedicada a pasificación y sin consistencia para conservarse en fresco- ensayaban la posibilidad de exportarla: "Las pérdidas sufridas el año pasado por varios especuladores de aquí en algunos embarques de uva moscatel hechos como experimento, no les ha desanimado para intentar otra vez la misma aventura, y tantos como 26.377 barriles de este fruto se han enviado el pasado verano a Inglaterra. El resultado ha demostrado que tantas cuantas partidas alcanzaron su destino en buenas condiciones han cosechado tan grandes ganancias como para justificar enteramente los peligros en los que incurrieron los embarcadores" (Wilkinson: 1878-79 LXX, p. 572). 
pal de la prolongación de la crisis de la viticultura pasera malagueña. Así, consideradas conjuntamente las viticulturas de ambas zonas y las condiciones dominantes en uno de sus grandes mercados, intuimos ya la respuesta del sector siguiendo presumiblemente las ventajas comparativas de cada producto vitícola en los mercados exteriores.

\subsection{Transformación en el sector vinicola}

Según nuestras cifras, la exportación de vino tuvo una tendencia creciente a lo largo de los años analizados, con un particular comportamiento expansivo durante el «período filoxérico» (1878-1909), especialmente en los años de vigencia del tratado franco-español. El negocio de exportar vinos no pareció, pues, salir mal parado durante la crisis, incluso después de terminarse el citado tratado.

Ya dijimos que el producto «vino de Málaga» no tenía por qué estar ligado necesariamente a la viticultura de la provincia; sin embargo, podemos considerar que, tendencialmente, la serie construida por Jiménez Blanco como de «Málaga» ${ }^{26}$ tiene más relación con aquél que la nuestra, que muestra, sencillamente, la exportación de cualquier caldo por el puerto malagueño. Comparadas ambas, lo que nos muestran es la crisis durante unos pocos años (1887-1895) de una actividad vinícola tradicional, presumiblemente vinculada a la viticultura autóctona pero, a la vez, que esos años fueron el gran momento de la comercialización en dicho puerto de los caldos del interior $\mathrm{y}$, posteriormente, una clara tendencia alcista en la exportación de cualquier clase de vino.

Así, pues, lo que ocurrió con el capítulo de la vinicultura malagueña (que es igual que decir todo el sector exportador vinícola de Andalucía Oriental) fue que durante la filoxera, espoleado por una demanda exterior firme de vinos y brandies a la que podía responder, se convirtió en un sector más estrictamente industrial y con poca conexión con la viticultura de la zona, pues desarrollaba su labor exportando directamente caldos del interior o componiendo vinos y brandies con dichos caldos, alcohol importado y, a lo sumo, con algo de mosto autóctono ${ }^{27}$; las combinaciones de unos ingre-

26 J. I. Jiménez Blanco (1986), p. 573.

"Durante la filoxera, la tradicional «composición de vinos» en la ciudad de Málaga llegó a ser cuantiosa, cosa que no dejaron de observar los representantes británicos: «La cantidad de vino fabricado en cada uno de esos años (1884 y 1885), de hecho, no puede haber sido menor de 300.000 galones, puesto que las exportaciones en 1884 alcanzaron los 2.206.758 galones, y en 1885 los 2.208 .090 galones..., pero no es necesario pretender que todas las uvas de las que se hace el vino de Málaga se crían en la provincia, ya que el mosto es frecuentemente obtenido de los distritos vecinos en los que existen viñedos» (Bidwell: $1886 \mathrm{LXV}$, p. 344). «El comercio de alcohol en este puerto debe estimarse al- 
dientes $\mathrm{u}$ otros dependerían de sus precios relativos ${ }^{20}$. En cualquier caso, los fabricantes y exportadores de vinos no tenían necesidad de impulsar la replantación de vides para vino en las tradicionales zonas costeras.

\subsection{Balance de conjunto}

En síntesis, los datos de exportación física analizados más arriba nos permiten observar que el sector de la producción, transformación y comercialización vitícola de Andalucía Oriental, que a mediados de los años setenta del siglo xIX beneficiaba un «volumen equivalente uva» ${ }^{29}$ de unas $85.000 \mathrm{Tms}$., tras una crisis de adaptación a condiciones cambiantes de los mercados exteriores, que afectó de forma dispar a sus diferentes ramas, se había recu. perado hacia 1909 y desde entonces fue de dimensión ligeramente superior a la etapa precedente (86.000 Tms. de media para 1908-1912).

No obstante, la lógica del ajuste determinó unos cambios en el sector que hicieron que la viticultura de Andalucía Oriental fuera muy diferente a la de antes de 1872. Entre ellos merecen destacarse dos:

a) El fruto fresco, siguiendo las indicaciones de los mercados, sustituyó en cuanto a volumen y valor la mayor parte de la exportación del fruto secado. Esto significó que el centro de gravedad de la viticultura en Andalucía Oriental pasara a la provincia de Almería, que se cubrió de plantaciones de vid desde Adra hasta la Garrucha.

b) En las otras ramas de la viticultura, especialmente en la vinícola,

rededor de 1.950 .000 litros, restando los 390.000 litros que son directamente consumidos, por ejemplo, en restaurantes, tabernas, etc., el resto está siendo aplicado a la composición y fortalecimiento de vinos» (Finn: 1892 LXXXIV, p. 3). Pasada la filoxera, la relación de la viticultura de la zona y la industria vinícola de la ciudad parecía ser menor que antes: «Málaga, aunque importante centro exportador y productor de vino, no es un gran distríto criador, puesto que la mayor parte de los mostos son importados de la Mancha o provincias centrales y de los distritos de Sevilla y Huelva. Como esos nuevos vinos son secos y los vinos que hicieron famosa a Malaga son casi exclusivamente dulces, su tratamiento en las bodegas de Malaga forma una industria muy importantew 75 taniforth: 1913 LXXII, p. 570).

${ }_{26}$ "Aunque la baratura del alcohol de patata extranjero importado frustra el beneficio de la reforma de los aranceles, algunos comerciantes de vino de Málaga que destilaban el alcohol del jugo de la uva todavía pueden producir su propio alcohol en términos ventajosos (...). El alcohol puro de vino puede ahora obtenerse en Málaga a 6 chelines por galón» (Finn: 1890-91 LXXXVII, pp. 770-778).

${ }^{29}$ Es decir, si considerásemos que todos los productos «vitícolas» exportados estuvieran producidos con uva. Para la conversión de las cantidades de pasa y de vino en el equivalente uva, hemos utilizado las proporciones siguientes: pasa $=1 / 3$ de uva, vino $=1 / 1,7$ de uva (para estas proporciones pueden verse Ch. Mignon, 1982, p. 454; L. Pellejero, 1986, pp. 26-27; J. Simpson, 1985, p. 191; J. I. Jiménez Blanco, 1985, vol. II, cuadro p. 978). 
las condiciones externas (capacidad de absorción del mercado, desventajas comparativas con otras partes del mundo, modificaciones en las costumbres alimentarias, evolución técnica y organizativa) disociaron los intereses de los transformadores y comercializadores de los productos, por un lado, y de los agricultores por otro, haciéndose inviable una gran parte de la viticultura tradicional ${ }^{30}$.

\section{LAS LECCIONES DE LOS RENDIMIENTOS MEDIOS Y LA RENTABILIDAD DE LAS EXPLOTACIONES}

Se podría pensar que la evolución del sector vitícola de Andalucía Oriental, que hemos resumido más arriba, se debió a causas extrañas a la racionalidad económica, como en alguna ocasión se ha afirmado para interpretar la casi aniquilación de la antigua viticultura malagueña ${ }^{31}$. Sin embargo, los datos de los cuadros 4 y 5 creemos que apuntan en otra dirección.

\section{CUADRO 4}

Estimación de la rentabilidad de $1 \mathrm{Ha}$. dedicada a producción de pasa en Málaga en el último decenio del siglo XIX

Coste del cultivo por año agrícola, cosecha, secado, empaquetado, portes, etc.

675,0

Rendimiento en fruto: $1.150 \mathrm{Kgs}$. de pasa (3.450 eq. uva)

Importe de la venta del fruto:

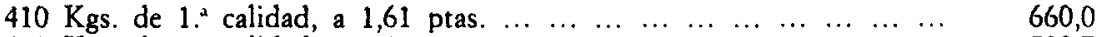

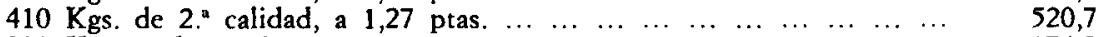

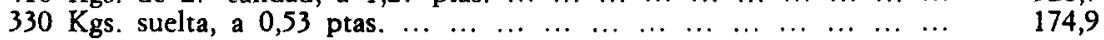

$\begin{array}{lllllllllllllllllll}\text { Total } & \ldots & \ldots & \ldots & \ldots & \ldots & \ldots & \ldots & \ldots & \ldots & \ldots & \ldots & \ldots & \ldots & \ldots & \ldots & \ldots & \ldots & 1.355,6\end{array}$

Lo que hace un beneficio bruto de explotación por hectárea de $\ldots \ldots \ldots \quad$ 680,6

Fuentes: Datos físicos: Informe del Cónsul Kimberley: 1894 LXXXVIII, p. 147. Precios: medias para los años 1892, 1893 y 1895, según los ICB de esos años (1893-94 XCVI; 1894 LXXXVIII; 1896 LXXXVIII). Aplicando precios no corrientes en el mercado en los años cercanos a su Informe, mucho más elevados, Kimberley obtiene unos rendimientos de $1.420 \mathrm{ptas} / \mathrm{Ha}$.

${ }^{30}$ J. Morilla Critz (1988 a), pp. 4.7 y 10-11.

"M. T. Carnero (1980), pp. 129-132. 


\section{CUADRO 5}

Estimación de la rentabilidad de $1 \mathrm{Ha}$. dedicada a producción de uva de embarque en Almeria en el primer decenio del siglo XX

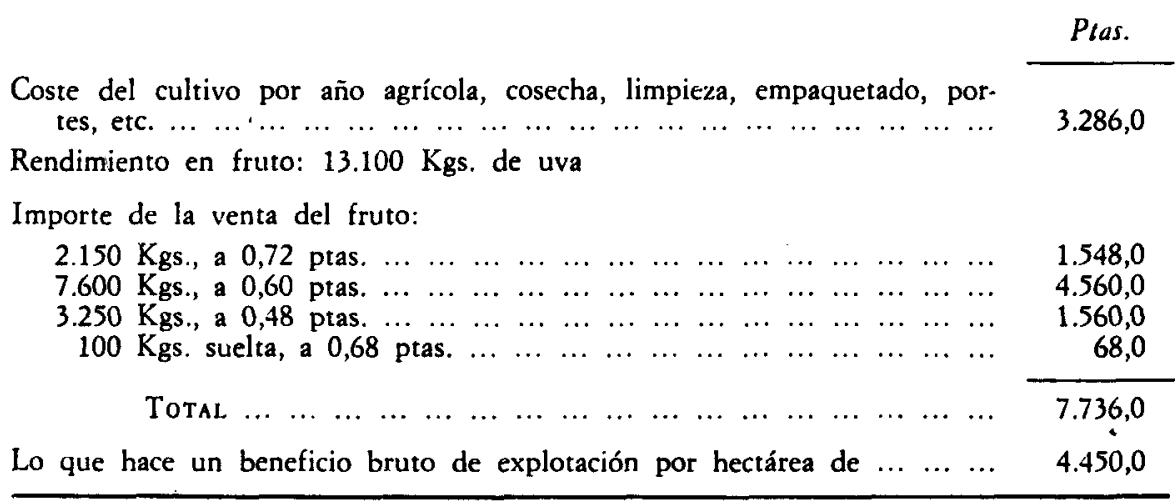

Fuentes: Datos físicos: Informe del Vicecónsul Murison: 1905 CXXVIII, p. 637. Precios: de Almería y la Garrucha de los años 1902, 1903, 1904, 1905, 1906 y 1908 (1903 LXXVIII, 1904 CIPtI, 1905 XCII, 1906 CXXVIII, 1908 CXVI y 1909 XCVIII).

A la vista de los datos de tales cuadros, sacamos la conclusión de que, en condiciones de explotaciones óptimas, o cercanas al óptimo, era más rentable la viticultura uvera de Almería que la de la pasa en Málaga en los años cercanos al comienzo del siglo $\mathrm{xx}$, aunque, eso sí, invirtiendo más capital circulante en una hectárea en Almería que en Málaga.

La base de esta diferente rentabilidad hay que encontrarla, a nuestro entender, en un conjunto de circunstancias que sumaban sus efectos positivos a favor de Almería y que, vistos comparativamente con Málaga, nos pueden enseñar algo con respecto a ambas viticulturas:

\subsection{El incremento de los rendimientos por bectárea en cada una de las zonas}

Tal como se observa en los cuadros 6,7 y 8 , la readaptación de la viticultura tras el período de crisis llevó aparejado un incremento de los rendimientos por hectárea de este cultivo en Andalucía Oriental, superior a la media española y a alguna otra zona mediterránea comparable en el aspecto vitícola, tal como Cataluña (cuadro 6). Sin embargo, en el caso de Andalucía 


\section{CUADRO 6}

\section{Rendimientos en uva por bectárea plantada de vid en Andalucia Oriental en 1909}

Producción estimada de uva de mesa (1)

Producción estimada de pasa/equivalente uva (1) $\ldots \ldots \ldots \ldots \ldots \ldots \ldots \ldots$

Producción estimada de vino/equivalente uva (1) $\ldots \ldots \ldots \ldots \ldots \ldots \ldots \ldots$

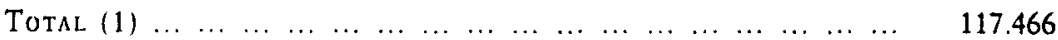

Superficie de viñedo (2) $\ldots \begin{array}{llllllllllllllll} & \ldots & \ldots & \ldots & \ldots & \ldots & \ldots & \ldots & \ldots & \ldots & \ldots & \ldots & \ldots & \ldots & \ldots & 42.612\end{array}$

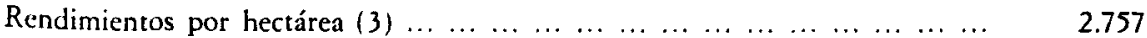

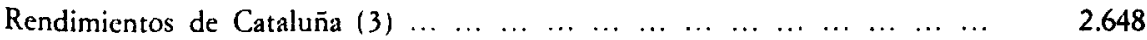

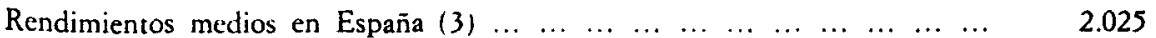

Noras: (1) Toneladas.

(2) Hectáreas.

(3) Kilogramos.

FuENTES: Las cantidades de uva de mesa y pasa son las correspondientes a Almería y Málaga de los cuadros 7 y 8 . La cantidad procedente del vino se deriva de las cantidades producidas de mosto, estimadas por la Junta Consultiva Agronómica (media de 1908-1910), en Almería, Granada, Jaén y Málaga, multiplicadas por 1,7. La estimación de Cataluña es de A. Balcells $(1980)$, p. 74, y es una media de 1908-1912. La estimación de España, de J. I. Jiménez Blanco (1986), p. 648 .

Oriental hubo una notable diferencia entre los casos de Almería y Málaga, pues en la primera de las provincias el incremento de los rendimientos fue espectacular, mientras que en la segunda, comparativamente, fue pequeño.

El incremento de los rendimientos por hectárea aparece, en principio, ligado a una reducción en ambas provincias de la superficie dedicada al viñedo; sin embargo, ésa sería una visión errónea de la transformación que se dio en el sector en la subregión, puesto que lo verdaderamente significativo fue que las hectáreas de vid existentes en Almería en 1909 tenían poco que ver con las anteriores a 1878 , pues aparecía en zonas que no habían estado dedicadas a este cultivo, como ocurrió en todo el valle bajo del Andarax y en el levante de la provincia, mientras que tradicionales zonas vitícolas acabaron desapareciendo para esta actividad. En Málaga, por el contrario, nos encontramos fundamentalmente con una limitación general de la superficie dedicada a este cultivo dentro de sus áreas de implantación tradicionales, recortándose extraordinariamente las hectáreas dedicadas a la producción de vino y pasa e incrementándose muy levemente las de vides para 


\section{CUADRO 7}

Rendimientos en uva por bectárea plantada de vid en la provincia de Málaga en 1878 y en 1909

\begin{tabular}{|c|c|c|}
\hline & 1878 & 1909 \\
\hline 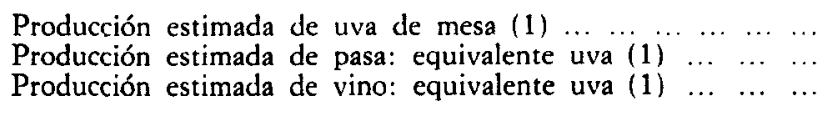 & $\begin{array}{r}770 \\
79.600 \\
54.116\end{array}$ & $\begin{array}{r}970 \\
33.900 \\
20.400\end{array}$ \\
\hline 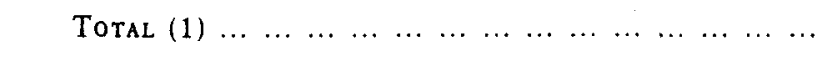 & 131.486 & 55.270 \\
\hline 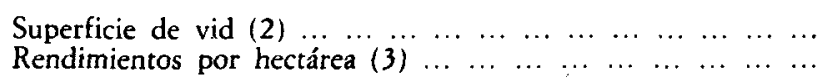 & $\begin{array}{r}112.872 \\
1.165\end{array}$ & $\begin{array}{r}24.180 \\
2.286\end{array}$ \\
\hline
\end{tabular}

Notas: (1) Toneladas.

(2) Hectáreas.

(3) Kilogramos.

\section{CUADRO 8}

Rendimientos en uva por bectárea plantada de vid en la provincia de Almería en 1878 y 1909

\begin{tabular}{|c|c|c|}
\hline & 1878 & 1909 \\
\hline 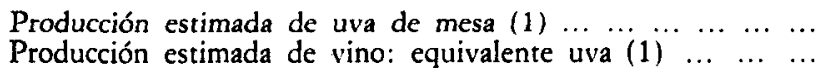 & $\begin{array}{l}9.500 \\
4.080\end{array}$ & $\begin{array}{r}54.800 \\
1.586\end{array}$ \\
\hline 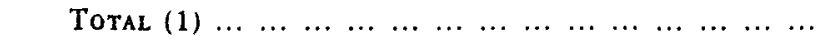 & 13.580 & 56.386 \\
\hline $\begin{array}{lllllllllllll}\text { Superficie de vid }(2) & \ldots & \ldots & \ldots & \ldots & \ldots & \ldots & \ldots & \ldots & \ldots & \ldots & \ldots & \ldots \\
\text { Rendimientos por hectárea }(3) & \ldots & \ldots & \ldots & \ldots & \ldots & \ldots & \ldots & \ldots & \ldots\end{array}$ & $\begin{array}{r}11.000 \\
1.235\end{array}$ & $\begin{array}{r}5.475 \\
10.299\end{array}$ \\
\hline
\end{tabular}

NotAs: (1) Toneladas.

(2) Hectáreas.

(3) Kilogramos.

FuENTES de los cuadros 7 y 8 : Véase nota ${ }^{32}$.

32 1) Las hectáreas de viñedo existentes en Málaga y Almería en 1878 y en 1909 pro. ceden de J. M. Guisado (1983), elaboradas en base a «La invasión filoxérica en España y estado en 1909 de la reconstitución del vin̄edom, informe realizado por la Junta Consultiva y Agronómica, Ministerio de Fomento (1911). Las cifras de Jiménez Blanco, procedentes de la misma fuente originaria, pero sólo desde 1889 , confirman la superficie de 1909. 2) La producción de pasa: medias para 1873-1878 y 1906-1912, de la serie ela- 
uva de consumo en fresco. Estamos, pues, ante dos tipos de ajustes ante la crisis muy diferentes.

Los elementos que permitieron la revolución productiva de la viticultura almeriense fueron de dos tipos: a) establecimiento en la zona de Almería de sistemas de cultivo y estructuras de explotación de las plantaciones vitícolas de carácter capitalista y modernizador, y b) adaptación de la nueva viticultura a las condiciones naturales de amplias zonas de la provincia.

Con respecto al primer elemento, algunos testimonios nos indican que en los años que siguieron a la etapa filoxérica y hasta 1914, los pequeños parraleros almerienses tradicionales vieron, primero, surgir ante ellos grandes explotadores y, después, cómo la lógica del mercado (entre 1901 y 1913, fundamentalmente) acabó imponiendo un proceso de concentración de la propiedad a costa de esos pequeños parraleros ${ }^{33}$. $\mathrm{Y}$ nos indican también que

borada por el autor, en base a la información consular (cuadro 2 del Apéndice estadístico). 3) Las producciones de uva fresca: Almería, estimación propia para los períodos 1877-1879 y 1907-1911, en base, fundamentalmente, a las cifras de exportación. Las informaciones que sobre producción dan los ICB son más dispersas que en el caso de la pasa de Málaga, pero muestran, para los años en que se dan, una correlación con aquéllas tan estrecha como en el caso de la pasa. Siguiendo el método de A. Gómez Mendoza, además, hemos sumado la media del volumen expedido hacia el interior (en 1909) de los años cercanos: 6.000 Tms. y una proporción equivalente a la exportación para 1878. Hemos estimado un consumo local anual equivalente a $0,40 \mathrm{Kgs} / \mathrm{habitante}$, en basc a la información consular. La producción, por la forma de cálculo, puede estar algo infravalorada en 1909, por dos razones fundamentalmente: el consumo local se hace según el conocimiento de "proporciones vendidas» en el mercado local, no, por tanto, el autoconsumo, y la exportación es la del puerto de Almería. En cualquier caso, los errores afectarían a las cantidades marginales, no al grueso de la estimación. Málaga: cifras de la exportación, más el consumo local, estimado de igual forma que en el caso anterior. 4) La producción de vino: para 1878, la cifra dada por el ingeniero agrónomo de la provincia Juan Alvarez y Sánchez (utilizada en todos los trabajos del tema), reducida a vino, pues la da en mosto. Según datos de explotaciones del Archivo de Protocolos de Málaga, hemos llegado a la conclusión de que para la época las «mermas» se situaban entre el 10 y el 12 por 100. Para 1909 partimos de la cifra de 11.600 , que es una extrapolación de las del ingeniero en basc a las cepas destruidas y reconstituidas. Estimamos que los posibles errores sean de sobrevaloración en las cantidades de $1909 \mathrm{e}$ infravaloración en las de 1878 Para Almería, la cifra de 1878 es una extrapolación a toda la provincia de la producción obtenida en la comarca de Adra, según datos del libro de J. L. Ruz Márquez (1981). $\mathrm{La}$ de 1909, de Jiménez Blanco, según datos del ingeniero agrónomo provincial.

${ }^{33} \mathrm{El}$ interés de plantadores capitalistas por el cultivo de parrales en Almería para el beneficio de uva de embarque, y su interés por las inversiones productivas, queda patente en las siguientes referencias de los ICB: «El distrito [Adra] ha prestado toda su atención al cultivo de viñas para la explotación de uxas y cantidades de elixos de gran antiguedad se han aurancado para plantar yiñas. Estas plantaciones son conducidas de la meiar forma posible, y se emplean grandes cantidades de alambre de bierro galyanizado. Hay también una buena utilización de abono artificial de Francia y de Bélgicas. (Agente Consular Benet: 1897 XCIII, p. 647). "Una compañía francesa llamada Credit Foncier et Agricole du Sud-Espaene con un capital de 5.000 .000 de francos, ha emprendido la irrigación de las tierras sesas del llamado Campo de Dalias de 100000 hectareas de extensión habiendo comprade para este proposito muy poderosos vegueros de agua en Sierra Nevadas (Benet: 1912-13 C, p. 327 ). «La predusción de yya de exportación se está incrementando conside- 
esas plantaciones fueron las que pudieron contar con una estructura adecuada y con los medios suficientes como para invertir en los sistemas de cultivo, regadíos y tratamiento del fruto que hicieron elevar los rendimientos.

El fenómeno de la adaptación de la nueva viticultura al medio natural se manifestó en el hecho de que las tradicionales plantaciones de los montes áridos de la Alpujarra almeriense y del interior desaparecieron $\mathrm{y}$, en su lugar, una nueva viticultura se concentró en tres de las grandes planicies costeras susceptibles, con mayores o menores dificultades, de ser irrigadas: Campo de Dalías, valle del Andarax y valle del Almanzora.

Este desplazamiento fue consecuencia, por una parte, de las características de los pies de cepa americanos que habrían de sustituir, por la filoxera, a las variedades autóctonas, que requerían suelos silíceos y susceptibles de riego ${ }^{34} \mathrm{y}$, por otra a las exigencias, en cuanto a insolación y temperatura, de las variedades de uva que, obtenidas por sucesivos cruces, reunían las mejores características para el embarque ${ }^{35}$. El ejemplo de lo ocurrido en la

rablemente, y una firma de Bilbao bien conocida ha comenzado la plantación de inmensos viñedos a lo large de la costa al sur de la Garruchay (Vicecónsul de la Garrucha, FordWalker: 1905 XCII, p. 559). «En orden a combatir esta feroz plaga [la filoxera], se ha importado vid americana que es capaz de resistir los ataques de la peste. El distinguido ingeniero y propietario catalán Don Francisco Casellas..., ha comprado unas 30.000 plantas, principalmente Riparia Solonis. Communis, Rupestrir Gaucis.... (Vicecónsul Lindsay: $1895 \mathrm{C}$, pp. 570-571). Los medios de comunicación, que se ocupaban habitualmente de los problemas del sector pasero, eran conscientes del proceso de concentración de la propiedad que se observaba en esta parcela de la agricultura almeriense: «Es una gran verdad, que mientras los productores van poco a poco perdiendo sus propiedades... el comercio se engrandece, los fabricantes de barriles adquieren pinguies ganancias, $y$ los exportadores se van quedando con toda la propiedad y formando grandes latilundios (EL $O b$. servador Mercantil, $31.8 .1905, \mathrm{p}$. 1). "Abrumados por la usura las malas cosechas y por los impuestos de la propiedad industrial, natural es que sucumban en primer término los pequeños propietarios... Los desposeidos pasan a ser asalariados con estas pequeñas parcelas acumuladas se forman inmensos latifundios. Continuando este proceso, todo el suelo llegará a encontrarse en pocas manos» (El Observador Mercantil 25-3-1206 \& \& 6). "Van poco a poco formando grandes latifundios, apropiándose de las pequeñas propiedades, resultando de todo esto que muchas familias tienen que emigrar al extranjero suelo, haciendo el vacío en los pueblos rurales, y otros retirándose de los campos, antes casi poblados y hoy reina en ellos la más espantosa soledad» (El Observador Mercantil, 8-11-1906, p. 7).

${ }^{34}$ J. I. Jiménez Blanco (1986), pp. 635-637; J. Guisado (1983), p. 184; C. Pellejero (1986), p. 572.

3s J. I. Jiménez Blanco (1986), pp. 597-606. Parece ser que también influyó en la experimentación con cruces 'la búsqueda de variedades más extemporáneas, que permitieran escapar de la coincidencia en los mercados de destino con otras frutas: «Empezando con la uva castiza se realizaron precios malos, o más bien pésimos... La causa de esto es principalmente la grandísima abundancia de las frutas de verano indígenas de nuestro país y de los países vecinos del Norte de Europa... Noviembre es el mes cuando se reciben los mayores cargamentos de manzana de América y abundancia de naranja de los países del Mediterráneo» (El Observador Mercantil, 14-10-1904, p. 4). "Se estudia la manera de criar mucho fruto, de que sea de gran aguante, de que se anticipe la madurez» (íd., 8-2-1905, p. 4). «Mal impresionados del negocio uvero empezamos esta crónica... en vista del desas- 
viticultura de la Alpujarra.granadina (bautizado con el gráfico apelativo de «segunda filoxera»), por realizar una precipitada y no selectiva replantación con cepas americanas en lugares no apropiados, posiblemente sirvió de experiencia en la provincia almeriense ${ }^{36}$.

Los rendimientos de la viticultura malagueña también se incrementaron a costa de abandonar en gran medida la explotación de las zonas marginales de la Axarquía y los Montes y concentrar las explotaciones en la Hoya de Málaga o valle del Guadalhorce, pero ese incremento de los rendimientos ya hemos visto que no dejó de ser modesto. Las razones de esta deficiencia creemos que hay que buscarlas en el mantenimiento, durante y tras la crisis, de una actividad vitícola «tradicional» en un doble sentido: en cuanto a los productos obtenidos (vino y pasas) y en cuanto a las dimensiones de las explotaciones ${ }^{37}$.

La elección, no obstante, en Málaga, por el mantenimiento de la viticultura tradicional, aunque más limitada que antes de la crisis, parecía lógica en las condiciones de entonces por las siguientes razones:

a) En esta zona era donde más tempranamente había aparecido la filoxera y, entonces, las primitivas replantaciones, que en el valle daban resultado con riparia, se hacían con la perspectiva, todavía de los viticultores tradicionales.

tre de que ha sido ohleto nuestra uva molinera y rosada y las pequeñas partidas enviadas de la más temprana ứa lcgítima, que siempre ha alcanzado precios muy elevados» (id., 31 . 8-1905, p. 1). Esta circunstancia seguramente influyó en el desarrollo de la variedad «legítima», que acabó imponiéndose, pero que requería un mayor gasto en mano de obra para el injerto, el engarpe, etc., y que fue la que se extendió, sobre todo, fuera de la zona tradicional del valle del Andarax.

36 «La filoxera también ha continuado sus fatales destrozos entre los viñedos, $y$ ha producido lo más destructivo en los alrededores de Baza. Es lamentable que los esfuerzos hechos en la Alpujarra por los empobrecidos propietarios para introducir la vid- riparia de América hayan resultado un señalado fracaso. Desde el principio parece haber habido un error en escoger esa particular especie de vid, que es adecuada a los distritos arenosos de las riberas bajas más que a los calcinados montes de gres de la Sierra. La ruina ha sido en consecuencia muy grande, y el resultado negativo de la replantación ha sido similar al de una segunda filoxera” (Vicecónsul de Granada, Davenhill: 1896 LXXXVIII, p. 735).

${ }^{37}$ En términos relativos, comparadas con las pequeñisimas parcelas familiares de la Axarquía y los Montes de Málaga, las fincas de Ta Vega, en buen número propledad de la burguesía ciudadana y trabajadas con mano de obra contratada, eran grandes, pero no lo eran en términos absolutos y comparables a las grandes plantaciones de las zonas de Montilla, Jerez o los nuevos parrales de Almeria. No existe un estudio cuantitativo al respecto, pero en ese carácter de "explotaciones relativamente grandes» tan sólo coinciden Pellejero (1986, pp. 572 y 575), Guisado (1983, pp. 178-179) y Mignon (1982, pp. 214 218). Además, las mayores explotaciones, que se constituyen entonces en la Hoya de Málaga por concentración de propiedades, se dedicaron fundamentalmente a «nuevos» cultivos como la caña de azúcar (Mignon, 1982, pp. 216-217). En cualquier caso, los mayores rendimientos vitícolas, que, según Pellejero, se situaban entre los 3.205 y $3.633 \mathrm{Kgs} / \mathrm{Ha}$. (considerando toda clase de terrenos), se conseguían en los distritos de la Vega. 
b) En Málaga se demostró que ni con una actividad de inversión en la producción de uva fresca que fuera similar a la que se desarrollaba en Almería, se podían obtener los rendimientos de la provincia oriental, por dos razones:

1. Los suelos y las características climatológicas no permitian un desarrollo de las mejores y más rentables especies de uva para embarque (la «casta de Ohanes» y la «legítima de embarque»), tan adecuadas, por el contrario, a los suelos sueltos y a la sequedad del ambiente de Almería.

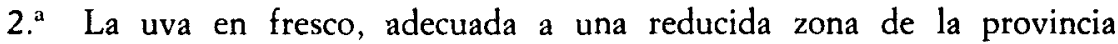
de Málaga ( «uva de Loja» en Coín, Alhaurín y Marbella), no podía alcanzar los rendimientos de aquellas otras variedades ${ }^{38}$.

De cualquier modo, todo ello no basta sino para explicar cómo los nuevos viticultores almerienses consiguieron ser eficientes dedicándose a la producción de uva de embarque, mientras que los malagueños, que no podían imitar a sus vecinos en esa rama de la viticultura, no lo fueron en las ramas «tradicionales» del negocio vitícola de Andalucía Oriental.

\subsection{Las condiciones de los mercados}

Estas fueron las que, en conjunción con lo anterior, pudieron determinar la suerte de ambos tipos de viticultura en aquellos años de crisis, puesto que en relación con la estructura de las explotaciones podían hacer viable o inviable, esperanzador o descorazonador, cada uno de los negocios vitícolas.

El período comprendido entre 1787 y 1909 debió de ser crucial para la toma de decisiones de inversión por los viticultores, por abarcar los años en los que el desarrollo de la filoxera disminuía el coste de oportunidad de los gastos necesarios para las posibles mejoras y transformaciones productivas, al desvalorizar el mantenimiento de las explotaciones antiguas, pero la inversión es una variable dependiente, entre otras cosas, de las expectativas en los mercados finales.

${ }^{38}$ La consecuencia de ello era que los parraleros malagueños no pudieran encajar la debilidad de precios que producía la superabundancia de fruto lanzada al mercado por Almería: "1907 resultó ser un buen año para esta clase de fruto, pues el distrito de Alhaurín donde se cultivan no sufrió mucho por las tormentas de septiembre y la cosecha entera se salvó y embaló. Los precios fueron bajos como consecuencia de la muy abundante cosecha de Almería, tanto que a finales de año era difícil encontrar compradores" (Haggard: 1908 CXVI, pp. 204-205). 
Los datos que poseemos sobre explotaciones paseras malagueñas, puestas en relación con el coste de la vida y los precios del producto de las mismas ${ }^{39}$, indican que, de entre las familiares, podian sobrevivir $y$, por tanto, reconstituirse, solamente aquellas explotaciones con los rendimientos que eran habituales en las zonas irrigadas de la vega, mientras que en la zona pasera más extensa hasta entonces (la Axarquía), la caída de los precios permitía una renta que, por una parte, era solamente un tercio del coste de alimentación de los que la obtenían y, por otra, la mitad de la que podrían obtener, dedicando el mismo tiempo a trabajar a jornal en otra actividad. El mantenimiento, muchos años después de rendimientos similares ${ }^{40}$, nos indica que para un gran sector de la viticultura pasera las desfavorables condiciones de los mercados analizadas anteriormente conducía inevitablemente a su desaparición.

La estructura y funcionalidad de la explotación vitivinícola en la pro-

39 Hemos podido llegar a las siguientes conclusiones para la explotación familiar de la zona malagueña: 1) A finales de siglo, el coste de alimentación de una familia campesina de cuatro miembros se encontraba situado entre 950 y 1.100 ptas. $(0,65-0,75$ ptas. persona/dia). 2) El jornal de un trabajador agricola en la zona se encontraba en torno a 1,5-2 ptas, lo que da un ingreso anual aproximado por trabajador de 600 ptas. 3) De acuerdo a los datos del cuadro 4 , una teórica explotación de vid de $1 \mathrm{Ha}$. en buenas tierras venía a tener la rentabilidad de un jornal y no alcanzaba, por sí misma, a alimentar a una familia campesina media. Pero, además, $1 \mathrm{Ha}$. de vid no podfa ser trabajada en forma familiar por una unidad de cuatro miembros: $1 \mathrm{Ha}$. de vid en Málaga eran 6,4 obradas de 1.000 cepas (siendo la «obrada» el espacio de vides sobre el que un hom. bre realizaba su trabajo en cada uno de los grupos de catorce días de media en que se realizaba el trabajo de la vid en el año). Por tanto, una explotación de una familia de cuatro miembros - de los que trabajaran tres- habría de ser de 0,5 Has. (por ello es completamente lógico el predominio en la Axarquía - como resulta de los datos de Guisado- de las explotaciones comprendidas entre 0,5 y $1 \mathrm{Ha}$.). Las cuentas, pues, de una explotación familiar situada en buenas tierras serían:

\begin{tabular}{|c|c|}
\hline & Ptas. \\
\hline $\begin{array}{l}\text { Gastos de explotación (excluyendo trabajo) } \\
\text { Ingresos } \\
\text { In }\end{array}$ & $\begin{array}{l}193,5 \\
677,5\end{array}$ \\
\hline
\end{tabular}

y esa renta venía a ser aproximadamente la mitad del coste de alimentación de la familia. 4) Si la explotación era de rendimientos similares a los de tierras de tercera clase en numerosas zonas de la provincia (unos $300 \mathrm{Kgs} / \mathrm{Ha}$.), el producto obtenido era de unas 350 ptas., lo que dejaba una renta neta de 160 ptas., que era la mitad de lo que los tres miembros potencialmente trabajadores de la unidad familiar podían obtener trabajando a jornal los cincuenta días en otro lugar. Coste de alimentación: ICB 1893-94 XCVI, pp. 8-9. Jornal del trabajador agrícola: ICB 1893-94 XCVVI, p. 8; A. Nadal Sánchez (1983), pp. 198-202; J. del Moral (1979), p. 78. Relación obradas/viñas/extensión: J. A. Lacomba (1974), p. 121, e ICB 1893-94 XCVI, p. 9. Rendimientos: cuadro 4 y C. Mignon (1982), p. 455, y C. Pellejero (1986), p. 576. Explotación media en la Axarquía: J. Guisado (1983), p. 178.

${ }^{40}$ Ch. Mignon (1982), p. 455. 
vincia malagueña era similar a la pasera; las condiciones desfavorables de los mercados ya vimos también que eran semejantes aunque por otras razones $y$, por tanto, el razonamiento puede ser el mismo y nos hace comprender que aquella viticultura tradicional de pequeñas explotaciones familiares situadas en las zonas montañosas «marginales», fuera abandonada y nutriera una fuerte oleada emigratoria.

A corto plazo, pues, sobrevivió sólo la viticultura de «altos rendimientos» de las tierras más feraces (la Hoya de Málaga) que era la zona, además, en donde radicaban las propiedades de la burguesía urbana. El capital que se requería para la reconstitución de los viñedos era ciertamente bastante limitado ${ }^{41}$, pero con respecto a la cuestión de si era posible incrementar más los rendimientos con una inversión innovadora mayor, verdaderamente hoy por hoy nos movemos en un terreno muy poco conocido. Lo que sí podemos saber es que hacia 1909 los rendimientos mínimos requeridos para cubrir los costes totales (explotación y amortización del capital invertido) ${ }^{42}$ se encontraban dentro de los que eran habituales en las mejores zonas antes de la crisis y, por tanto, parece lógica una reestructuración del sector que se basara en una mera reducción de la superficie dedicada a la vid.

En el caso de la uva de Almería, ya hemos visto que las expectativas eran diferentes porque el momento de la filoxera coincidía con una extraordinaria expansión de la demanda ${ }^{43}$, pero para obtener rentabilidad en las condiciones de precios dadas (cuadro 11 del Apéndice estadístico) se reque-

" La inversión requerida para poner en cultivo $1 \mathrm{Ha}$. hasta comenzar a rendir al quinto año era, según nuestros cálculos, la siguiente:

\begin{tabular}{|c|c|}
\hline & Ptas. \\
\hline 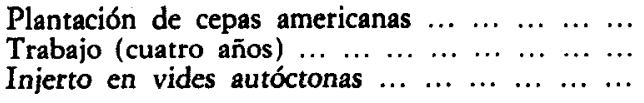 & $\begin{array}{l}479,25 \\
639,00 \\
159,75\end{array}$ \\
\hline $\begin{array}{lllllllllllll}\text { Total } & \ldots & \ldots & \ldots & \ldots & \ldots & \ldots & \ldots & \ldots & \ldots & \ldots & \ldots\end{array}$ & $1.278,00$ \\
\hline
\end{tabular}

FuENTES: Id. cuadro 4.

12 Teniendo en cuenta para Málaga y Almería la misma composición orgánica del capital invertido y un período de amortización de dicho capital de diez años, la rentabili. dad media de la explotación pasera malagueña (según el cuadro 4) era del 68 por 100, y de la explotación uvera almeriense, del 99,53 por 100 , requiriéndose para alcanzar el punto muerto de explotación $691 \mathrm{Kgs} / \mathrm{Ha}$. en la primera y $6.565 \mathrm{Kgs} / \mathrm{Ha}$. en la segunda

${ }^{43}$ Las expectativas, a pesar de la filoxera, eran tan buenas que se podía vender el fruto de los viñedos filoxerados y, en todo caso, justificaba la inversión en replantaciones con cepas dedicadas a la obtención de uva, no sólo en Almería, sino en Málaga y Granada: «En Glasgow se han obtenido resultados relativamente satisfactorios... mucha de la uva allí vendida procedía de Dalias, distrito que ha podido este año mandar también un gran número de marcas en buena condición y lo confirman los cables más recientes de 
rían unos rendimientos que estaban por encima de los anteriores a la crisis. Mientras los precios fueron extraordinariamente altos (hasta 1901 aproximadamente) las posibilidades de explotación parecían alcanzar tanto a pequeños parraleros como a los cosecheros capitalistas. Después, la superproducción y las prácticas monopolísticas en los mercados tradicionales de destino (Londres, principalmente) impondrán una caída de los precios que producirá en la zona un fenómeno de concentración de la propiedad y del sector comercial que lo adecuó a las condiciones de los mercados con una pequeña reducción de la superficie cultivada, aunque sí con una estructura de la empresa diferente.

\section{CONCLUSIONES}

Consideramos, pues, que en el período de la «Gran depresión» de finales del xIx, la viticultura de Andalucía Oriental se transformó siguiendo las condiciones más adecuadas de rentabilidad según los estímulos del mercado, en medio de un proceso general de incremento de los rendimintos, con unos comportamientos agrícolas y comerciales más capitalistas a los anteriores a la crisis, y en el que parece insustancial la pregunta sobre un mayor o menor espíritu emprendedor de sus agentes en unas áreas u otras.

Por supuesto que todo este cambio tuvo un componente sociológico y hasta antropológico. Puesto que arrastraba, tanto en Málaga como en Almería, la ruina de los pequeños viticultores tradicionales, de los pequeños intcrmediarios entre éstos y los asentadores y, también, la ruina de la economía de montaña a favor de la de las vegas y planicies costeras.

\footnotetext{
Nueva York... La filoxera principió en Dalías y algunas de las mejores marcas que siguen llegando bien salen de parrales afiloxerados» (La Crónica Meridional, 25-11-1893). «Las relaciones estadísticas muestran que ha habido un considerable incremento en la cantidad de uvas exportadas en el año 1890 comparado con el año precedente. Aunque no hay duda de que la filoxera está llegando firmemente con sus destructivos efectos a los viñedos de este distrito, la replantación con vides "riparia" está siendo llevada a cabo extensamente por algunos ricos propietarios» (Finn: 1892 LXXXIV, p. 130). «La plantación de viña de uva está en crecimiento. Han sido embarcados algunos cientos de barriles este año, y hace tiempo que se espera se dará un gran tráfico en este distrito» (Agente Consular Villar, de Motril: 1897 XCIII, p. 652).
} 


\section{APENDICE ESTADISTICO}

\section{CUADRO 1}

Exportación de pasa de Málaga

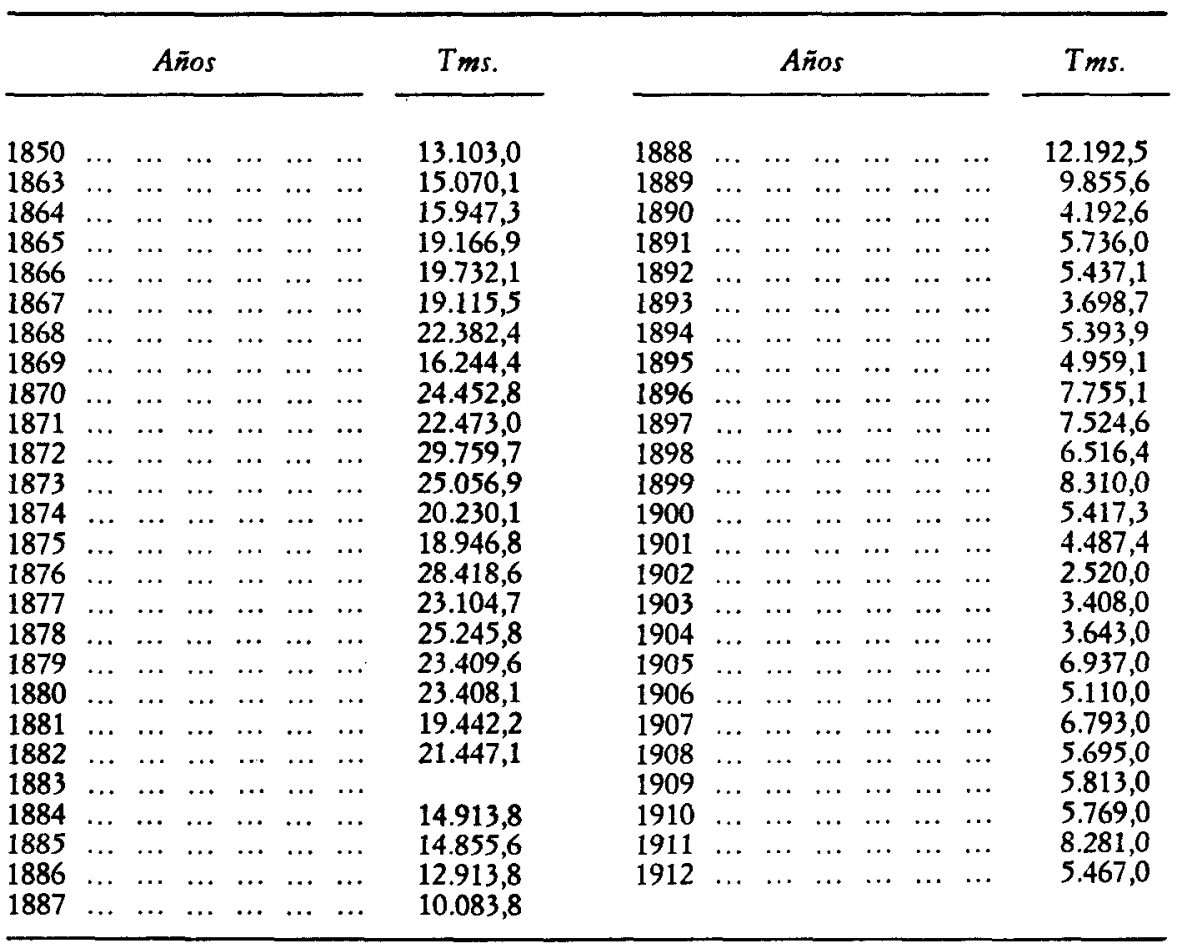

Funntes: ICB y, para 1850, Avisador Malagueño. 
CAMBIOS EN LA VITICULTURA DE ANDALUCIA ORIENTAI.

\section{CUADRO 2}

Cosechas estimadas de pasa de Málaga

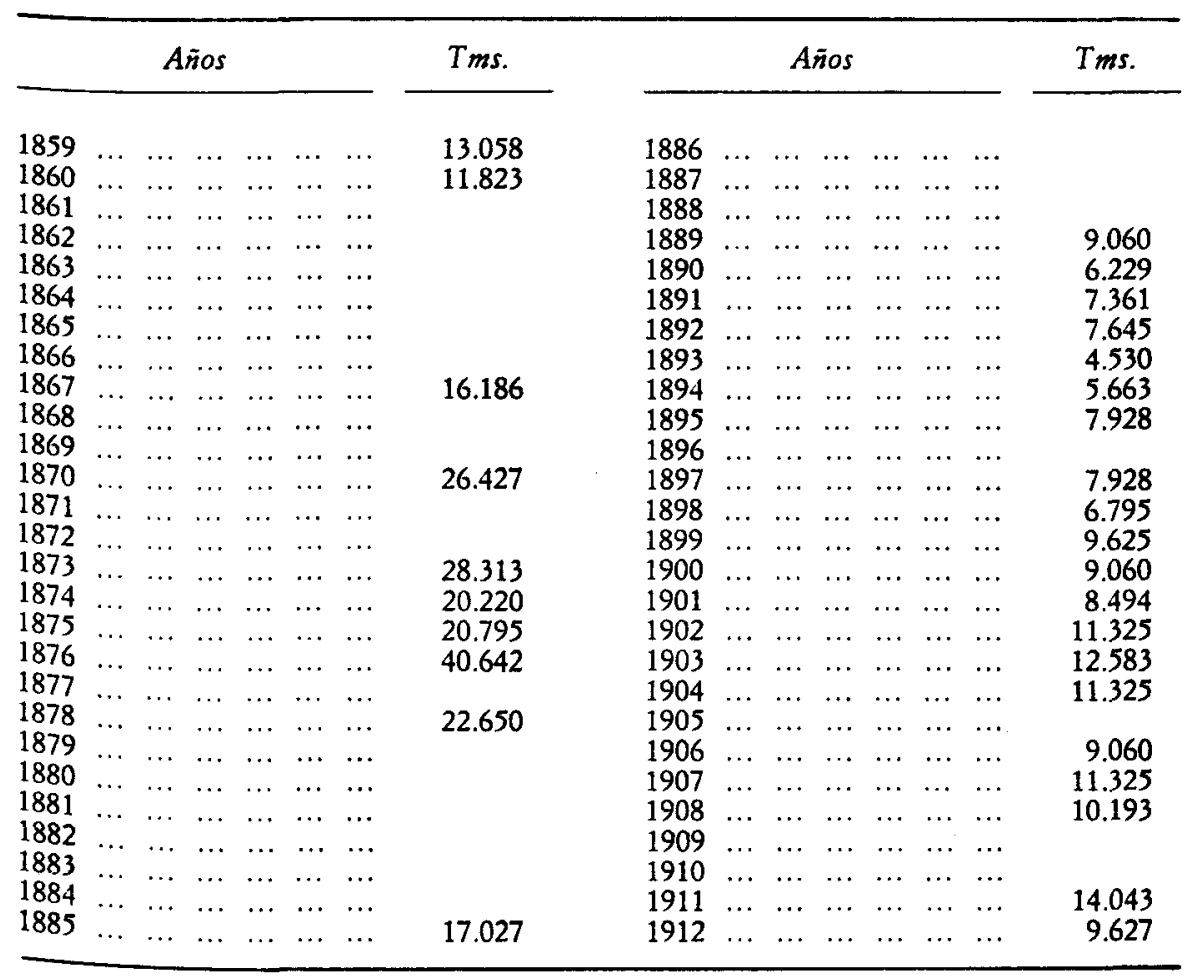

Fuentes: ICB y, para 1867, 1870, 1874 y 1875, Avisador Malagueño. 


\section{CUADRO 3}

Exportación de uva de Málaga

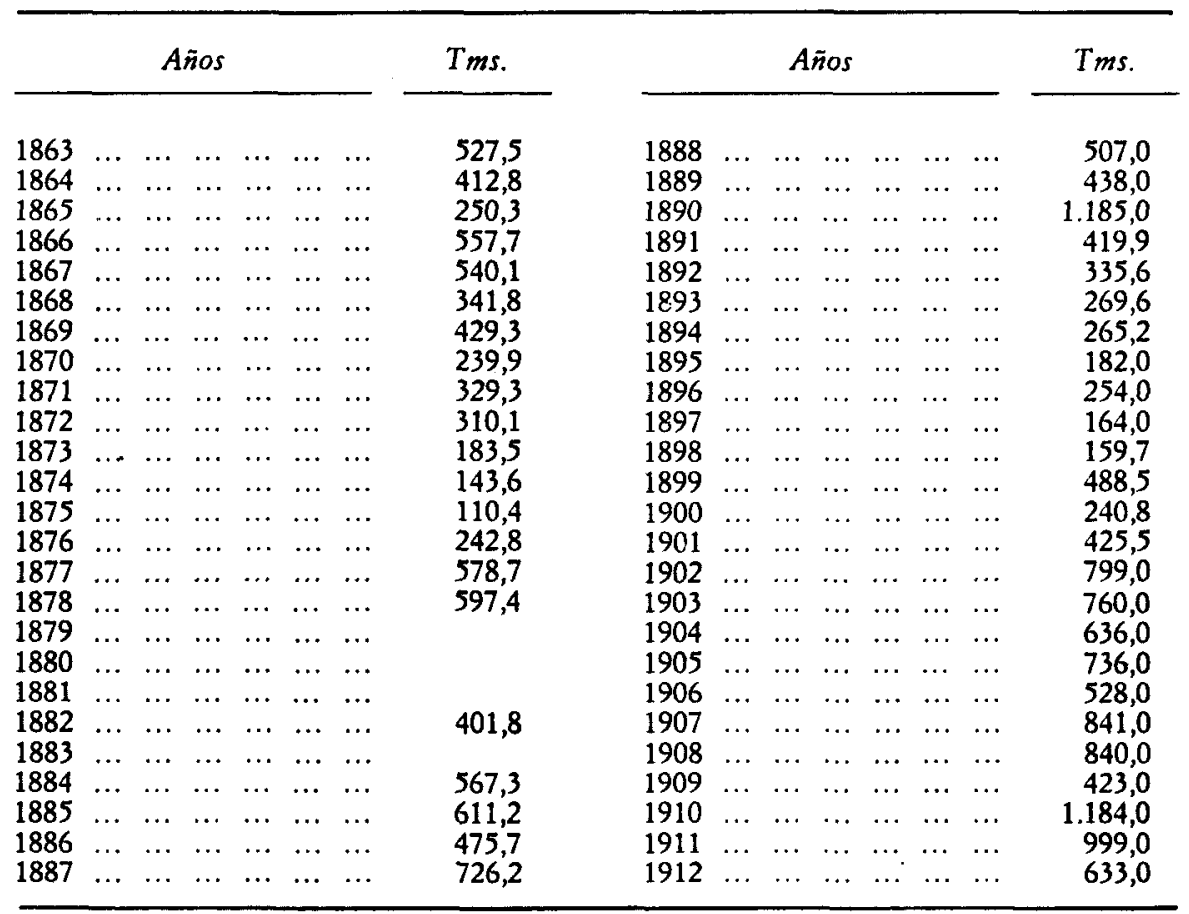

FUENTES: ICB. 


\section{CUADRO 4}

Exportación de vino desde Málaga

\begin{tabular}{|c|c|c|c|c|c|c|c|c|c|c|c|c|c|}
\hline & $A \tilde{n} O S$ & & & & Hls. & & & & $\tilde{n}$ os & & & & Hls. \\
\hline $\begin{array}{ll}1863 & \ldots \\
1864 & \ldots \\
1865 & \ldots \\
1866 & \ldots \\
1867 & \ldots \\
1868 & \ldots \\
1869 & \ldots \\
1870 & \ldots \\
1871 & \ldots \\
1872 & \ldots \\
1873 & \ldots \\
1874 & \ldots \\
1875 & \ldots \\
1876 & \ldots \\
1877 & \ldots \\
1878 & \ldots \\
1879 & \ldots \\
1880 & \ldots \\
1881 & \ldots \\
1882 & \ldots \\
1883 & \ldots \\
1884 & \ldots \\
1885 & \ldots \\
1886 & \ldots \\
1887 & \ldots\end{array}$ & $\begin{array}{ll}\ldots & \ldots \\
\ldots & \ldots \\
\ldots & \ldots \\
\ldots & \ldots \\
\ldots & \ldots \\
\ldots & \ldots \\
\ldots & \ldots \\
\ldots & \ldots \\
\ldots & \ldots \\
\ldots & \ldots \\
\ldots & \ldots \\
\ldots & \ldots \\
\ldots & \ldots \\
\ldots & \ldots \\
\ldots & \ldots \\
\ldots & \ldots \\
\ldots & \ldots \\
\ldots & \ldots \\
\ldots & \ldots \\
\ldots & \ldots \\
\ldots & \ldots \\
\ldots & \ldots \\
\ldots & \ldots \\
\ldots & \ldots \\
\ldots & \ldots\end{array}$ & $\begin{array}{l}\ldots \\
\ldots \\
\ldots \\
\ldots \\
\ldots \\
\ldots \\
\ldots \\
\ldots \\
\ldots \\
\ldots \\
\ldots \\
\ldots \\
\ldots \\
\ldots \\
\ldots \\
\ldots \\
\ldots \\
\ldots \\
\ldots \\
\ldots \\
\ldots \\
\ldots \\
\ldots \\
\ldots\end{array}$ & 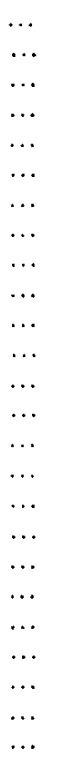 & $\begin{array}{l}\ldots \\
\ldots \\
\ldots \\
\ldots \\
\ldots \\
\ldots \\
\ldots \\
\ldots \\
\ldots \\
\ldots \\
\ldots \\
\ldots \\
\ldots \\
\ldots \\
\ldots \\
\ldots \\
\ldots \\
\ldots \\
\ldots \\
\ldots \\
\ldots \\
\ldots \\
\ldots\end{array}$ & $\begin{array}{r}64.619 \\
62.419 \\
66.815 \\
68.270 \\
53.373 \\
50.941 \\
69.893 \\
43.606 \\
60.502 \\
64.681 \\
73.125 \\
81.306 \\
57.695 \\
57.337 \\
69.653 \\
51.002 \\
61.431 \\
69.804 \\
84.305 \\
87.937 \\
95.860 \\
108.411 \\
105.216 \\
92.523 \\
90.251\end{array}$ & $\begin{array}{l}1888 \\
1889 \\
1890 \\
1891 \\
1892 \\
1893 \\
1894 \\
1895 \\
1896 \\
1897 \\
1898 \\
1899 \\
1900 \\
1901 \\
1902 \\
1903 \\
1904 \\
1905 \\
1906 \\
1907 \\
1908 \\
1909 \\
1910 \\
1911 \\
1912\end{array}$ & 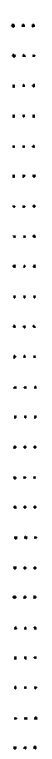 & $\begin{array}{l}\ldots \\
\ldots \\
\ldots \\
\ldots \\
\ldots \\
\ldots \\
\ldots \\
\ldots \\
\ldots \\
\ldots \\
\ldots \\
\ldots \\
\ldots \\
\ldots \\
\ldots \\
\ldots \\
\ldots \\
\ldots \\
\ldots \\
\ldots \\
\ldots \\
\ldots \\
\ldots \\
\ldots \\
\ldots\end{array}$ & 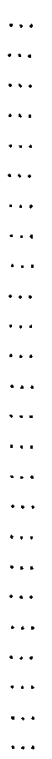 & $\begin{array}{l}\ldots \\
\ldots \\
\ldots \\
\ldots \\
\ldots \\
\ldots \\
\ldots \\
\ldots \\
\ldots \\
\ldots \\
\ldots \\
\ldots \\
\ldots \\
\ldots \\
\ldots \\
\ldots \\
\ldots \\
\ldots \\
\ldots \\
\ldots \\
\ldots \\
\ldots \\
\ldots \\
\ldots \\
\ldots\end{array}$ & $\begin{array}{l}\ldots \\
\ldots \\
\ldots \\
\ldots \\
\ldots \\
\ldots \\
\ldots \\
\ldots \\
\ldots \\
\ldots \\
\ldots \\
\ldots \\
\ldots \\
\ldots \\
\ldots \\
\ldots \\
\ldots \\
\ldots \\
\ldots \\
\ldots \\
\ldots \\
\ldots \\
\ldots \\
\ldots \\
\ldots\end{array}$ & $\begin{array}{l}\ldots \\
\ldots \\
\ldots \\
\ldots \\
\ldots \\
\ldots \\
\ldots \\
\ldots \\
\ldots \\
\ldots \\
\ldots \\
\ldots \\
\ldots \\
\ldots \\
\ldots \\
\ldots \\
\ldots \\
\ldots \\
\ldots \\
\ldots \\
\ldots \\
\ldots \\
\ldots \\
\ldots\end{array}$ & $\begin{array}{r}84.420 \\
95.445 \\
90.917 \\
107.929 \\
237.210 \\
63.713 \\
75.211 \\
71.567 \\
96.386 \\
87.978 \\
89.386 \\
103.953 \\
77.563 \\
72.471 \\
66.957 \\
64.347 \\
66.290 \\
119.930 \\
107.860 \\
103.850 \\
147.260 \\
103.100 \\
118.050 \\
140.000 \\
101.330\end{array}$ \\
\hline
\end{tabular}

Fuentes: ICB y, para 1879.81 y 1883, Crisis agricola y pecuaria. 


\section{CUADRO 5 \\ Exportación de uva de Almeria}

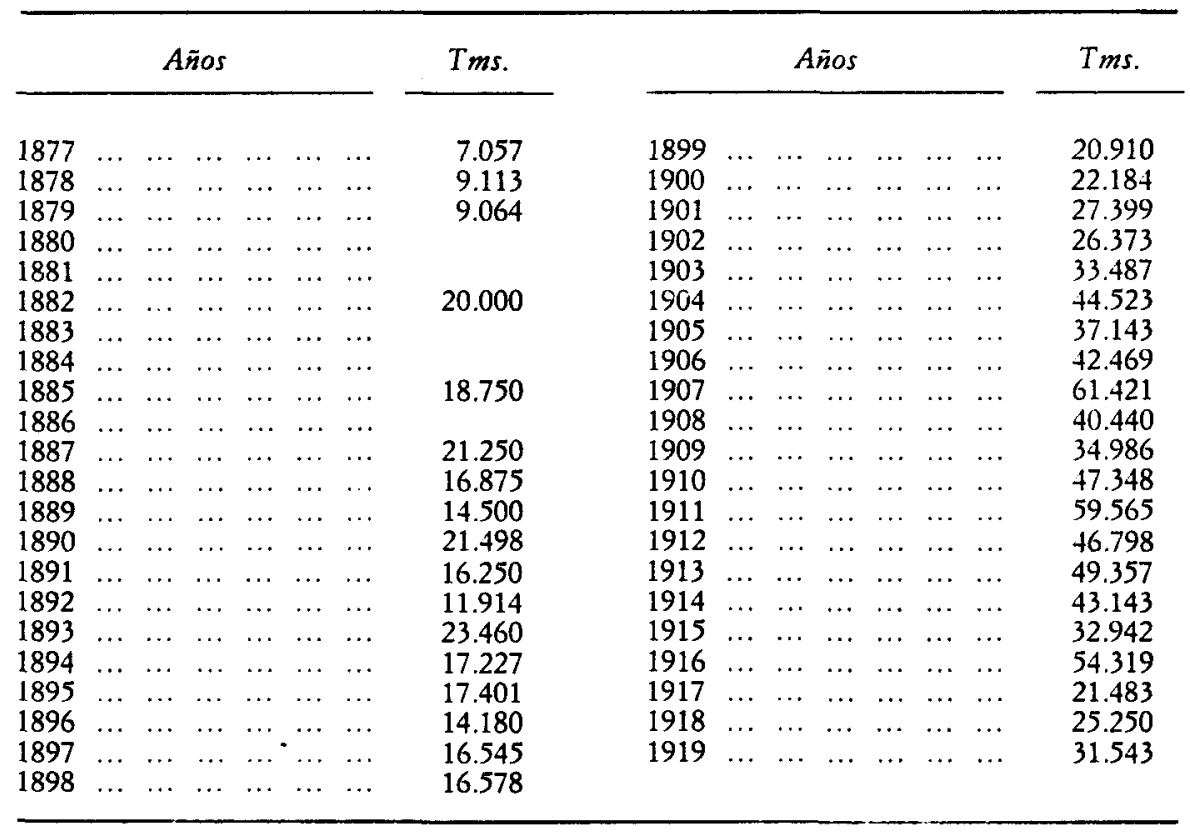

Fuentes: ICB y, para 1913-19, Méndez González y Sánchez Picón. 


\section{CUADRO 6}

Importación de alcobol en Málaga

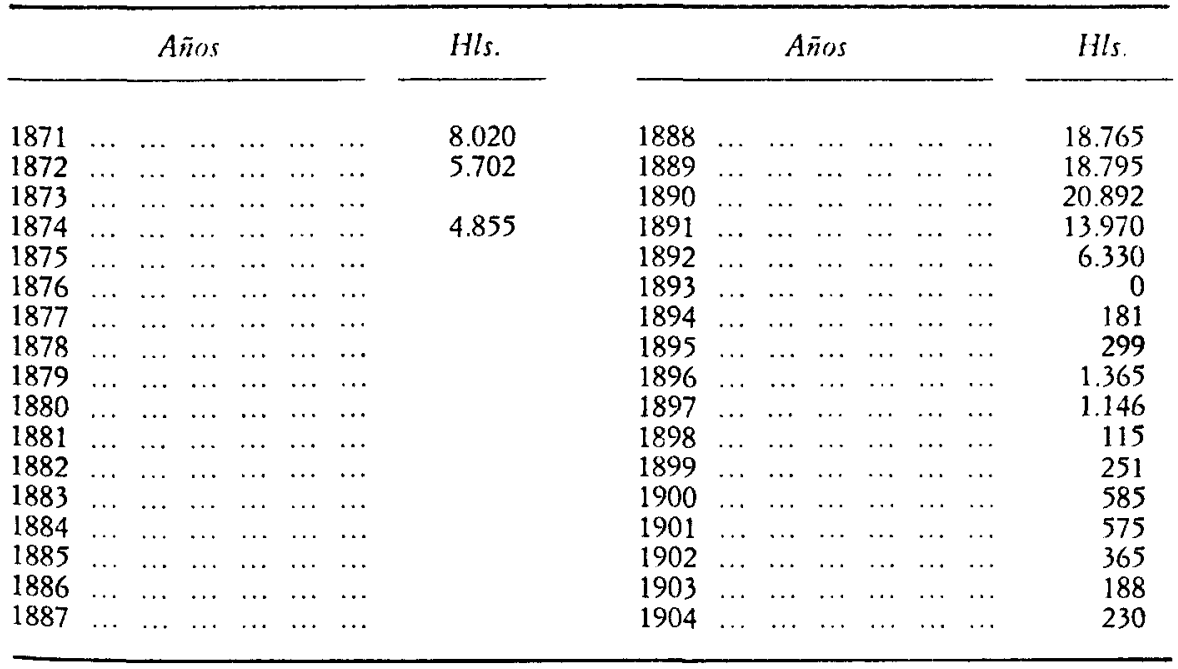

Fuentes: ICB. 


\section{CUADRO 7}

Evolución de la exportación de pasa de Málaga por áreas de destino (1868-1882)

(Indices, base $100=1882$ )

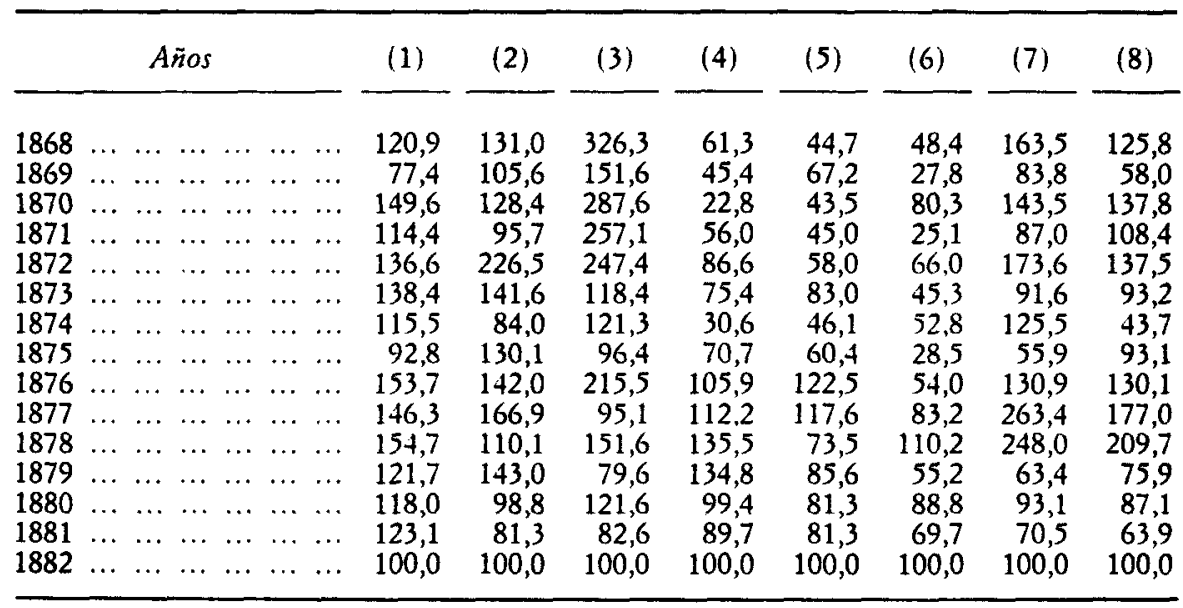

Notas: (1) Estados Unidos.

(2) Gran Bretaña.

(3) Colonias británicas.

(4) Francia.

(5) Europa del Norte.

(6) Mediterráneo y Portugal.

(7) América del Sur.

(8) Cabotaje e interior.

FUENTES: ICB. 


\section{CUADRO 8}

Distribución de la exportación de la uva de Almeria (1877-1912)

\begin{tabular}{|c|c|c|c|}
\hline \multirow[b]{2}{*}{ Areas geográficas y puertos de destino } & \multicolumn{3}{|c|}{ Medias anuales en cada periodo (Tms.) } \\
\hline & $1877-1892$ & 1893.1902 & $1903-1912$ \\
\hline 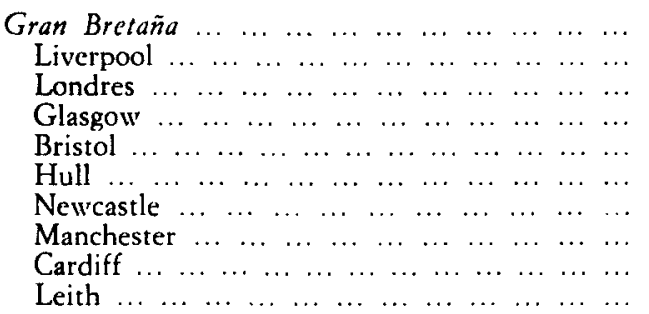 & $\begin{array}{r}12.591 \\
5.688 \\
5.060 \\
1.720 \\
88 \\
35\end{array}$ & $\begin{array}{r}15.022 \\
7.691 \\
4.912 \\
1.953 \\
330 \\
883 \\
120 \\
15\end{array}$ & $\begin{array}{r}22.759 \\
10.523 \\
6.453 \\
3.451 \\
695 \\
1.650 \\
713 \\
460 \\
485 \\
17\end{array}$ \\
\hline $\begin{array}{cccccccccccc}\text { Estados Unidos } & \ldots & \ldots & \ldots & \ldots & \ldots & \ldots & \ldots & \ldots & \ldots & \ldots \\
\quad \text { Nueva York } & \ldots & \ldots & \ldots & \ldots & \ldots & \ldots & \ldots & \ldots & \ldots & \ldots \\
\text { Boston } & \ldots & \ldots & \ldots & \ldots & \ldots & \ldots & \ldots & \ldots & \ldots & \ldots & \ldots \\
\text { Filadelfia } & \ldots & \ldots & \ldots & \ldots & \ldots & \ldots & \ldots & \ldots & \ldots & \ldots & \ldots \\
\text { Baltimore } & \ldots & \ldots & \ldots & \ldots & \ldots & \ldots & \ldots & \ldots & \ldots & \ldots & \ldots \\
\text { Nueva Orleans } & \ldots & \ldots & \ldots & \ldots & \ldots & \ldots & \ldots & \ldots & \ldots\end{array}$ & $\begin{array}{r}3.750 \\
3.308 \\
397\end{array}$ & $\begin{array}{r}3.806 \\
3.300 \\
362 \\
133 \\
11\end{array}$ & $\begin{array}{r}15.135 \\
14.015 \\
908 \\
182 \\
8 \\
22\end{array}$ \\
\hline 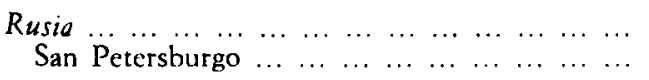 & $\begin{array}{l}112 \\
112\end{array}$ & $\begin{array}{l}72 \\
72\end{array}$ & \\
\hline $\begin{array}{rlllllllllll}\text { Alemania } & \ldots & \ldots & \ldots & \ldots & \ldots & \ldots & \ldots & \ldots & \ldots & \ldots & \ldots \\
\text { Hamburgo } & \ldots & \ldots & \ldots & \ldots & \ldots & \ldots & \ldots & \ldots & \ldots & \ldots \\
\text { Bremen } & \ldots & \ldots & \ldots & \ldots & \ldots & \ldots & \ldots & \ldots & \ldots & \ldots & \ldots\end{array}$ & & $\begin{array}{l}242 \\
242\end{array}$ & $\begin{array}{r}4.647 \\
4.371 \\
276\end{array}$ \\
\hline $\begin{array}{rllllllllll}\text { Paises Escandinavos } & \ldots & \ldots & \ldots & \ldots & \ldots & \ldots & \ldots & \ldots \\
\quad \text { Copenhage } & \ldots & \ldots & \ldots & \ldots & \ldots & \ldots & \ldots & \ldots & \ldots & \ldots \\
\text { Christiania } & \ldots & \ldots & \ldots & \ldots & \ldots & \ldots & \ldots & \ldots & \ldots & \ldots \\
\text { Estocolmo } & \ldots & \ldots & \ldots & \ldots & \ldots & \ldots & \ldots & \ldots & \ldots & \ldots \\
\text { Gotemburgo } & \ldots & \ldots & \ldots & \ldots & \ldots & \ldots & \ldots & \ldots & \ldots & \ldots \\
\end{array}$ & & $\begin{array}{r}115 \\
56 \\
22 \\
54 \\
23\end{array}$ & $\begin{array}{l}253 \\
154 \\
? \\
? \\
?\end{array}$ \\
\hline $\begin{array}{rrrrrrrrrrrrr}\text { Beilgica } & \ldots & \ldots & \ldots & \ldots & \ldots & \ldots & \ldots & \ldots & \ldots & \ldots & \ldots & \ldots \\
\text { Amberes } & \ldots & \ldots & \ldots & \ldots & \ldots & \ldots & \ldots & \ldots & \ldots & \ldots & \ldots\end{array}$ & & & $\begin{array}{l}32 \\
32\end{array}$ \\
\hline 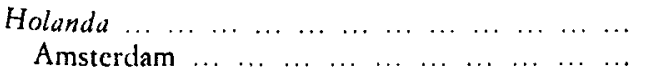 & & & $\begin{array}{l}64 \\
64\end{array}$ \\
\hline 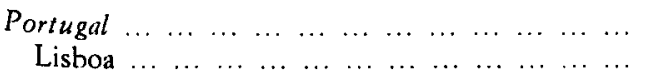 & & & $\begin{array}{l}3 \\
3\end{array}$ \\
\hline 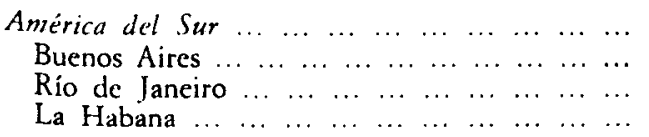 & & & $\begin{array}{r}231 \\
44 \\
149 \\
38\end{array}$ \\
\hline $\begin{array}{lllllllllllll}E_{\text {spaña }} & \ldots & \ldots & \ldots & \ldots & \ldots & \ldots & \ldots & \ldots & \ldots & \ldots & \ldots & \ldots\end{array}$ & & 36 & 174 \\
\hline 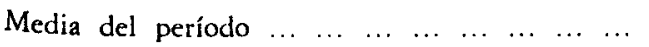 & 16.408 & 19.293 & 43.298 \\
\hline
\end{tabular}

FUENTES: ICB. 


\section{CUADRO 9}

Distribución porcentual de la exportación de uva de Almeria por áreas geográticas

\begin{tabular}{|c|c|c|c|}
\hline \multirow[b]{2}{*}{ Areas } & \multicolumn{3}{|c|}{$\%$ cun respecto al total } \\
\hline & $1877-1892$ & 1893.1902 & $1903-1912$ \\
\hline $\begin{array}{llllllllllll}\text { Gran Bretaña } & \ldots & \ldots & \ldots & \ldots & \ldots & \ldots & \ldots & \ldots & \ldots & \ldots\end{array}$ & 76,74 & 77,86 & 52,56 \\
\hline $\begin{array}{llllllllll}\text { Estados Unidos } & \ldots & \ldots & \ldots & \ldots & \ldots & \ldots & \ldots & \ldots & \ldots\end{array}$ & 22,58 & 19,73 & 34,96 \\
\hline $\begin{array}{lllllllllllll}\operatorname{Rusia} & \ldots & \ldots & \ldots & \ldots & \ldots & \ldots & \ldots & \ldots & \ldots & \ldots & \ldots & \ldots\end{array}$ & 0,68 & 0,37 & \\
\hline $\begin{array}{llllllllllll}\text { Alemania } & \ldots & \ldots & \ldots & \ldots & \ldots & \ldots & \ldots & \ldots & \ldots & \ldots & \ldots\end{array}$ & & 1,25 & 10,73 \\
\hline $\begin{array}{lllllllll}\text { Países Escandinavos } & \ldots & \ldots & \ldots & \ldots & \ldots & \ldots & \ldots & \ldots\end{array}$ & & 0,60 & 0,58 \\
\hline $\begin{array}{lllllllllllll}\text { España } & \ldots & \ldots & \ldots & \ldots & \ldots & \ldots & \ldots & \ldots & \ldots & \ldots & \ldots & \ldots\end{array}$ & & 0,19 & 0,40 \\
\hline $\begin{array}{llllllllllllll}\text { Bélgica } & \ldots & \ldots & \ldots & \ldots & \ldots & \ldots & \ldots & \ldots & \ldots & \ldots & \ldots & \ldots\end{array}$ & & & 0,07 \\
\hline $\begin{array}{llllllllllllll}\text { Holanda } & \ldots & \ldots & \ldots & \ldots & \ldots & \ldots & \ldots & \ldots & \ldots & \ldots & \ldots & \ldots\end{array}$ & & & 0,15 \\
\hline $\begin{array}{llllllllllllll}\text { Portugal } & \ldots & \ldots & \ldots & \ldots & \ldots & \ldots & \ldots & \ldots & \ldots & \ldots & \ldots & \ldots\end{array}$ & & & 0,01 \\
\hline \multirow[t]{2}{*}{$\begin{array}{llllllllll}\text { América del Sur } & \ldots & \ldots & \ldots & \ldots & \ldots & \ldots & \ldots & \ldots & \ldots\end{array}$} & & & 0,54 \\
\hline & 100,00 & 100,00 & 100,00 \\
\hline
\end{tabular}

FuENTES: ICB. 


\section{CUADRO 10}

Precios de la pasa de Málaga (variedad «lecho corriente»)

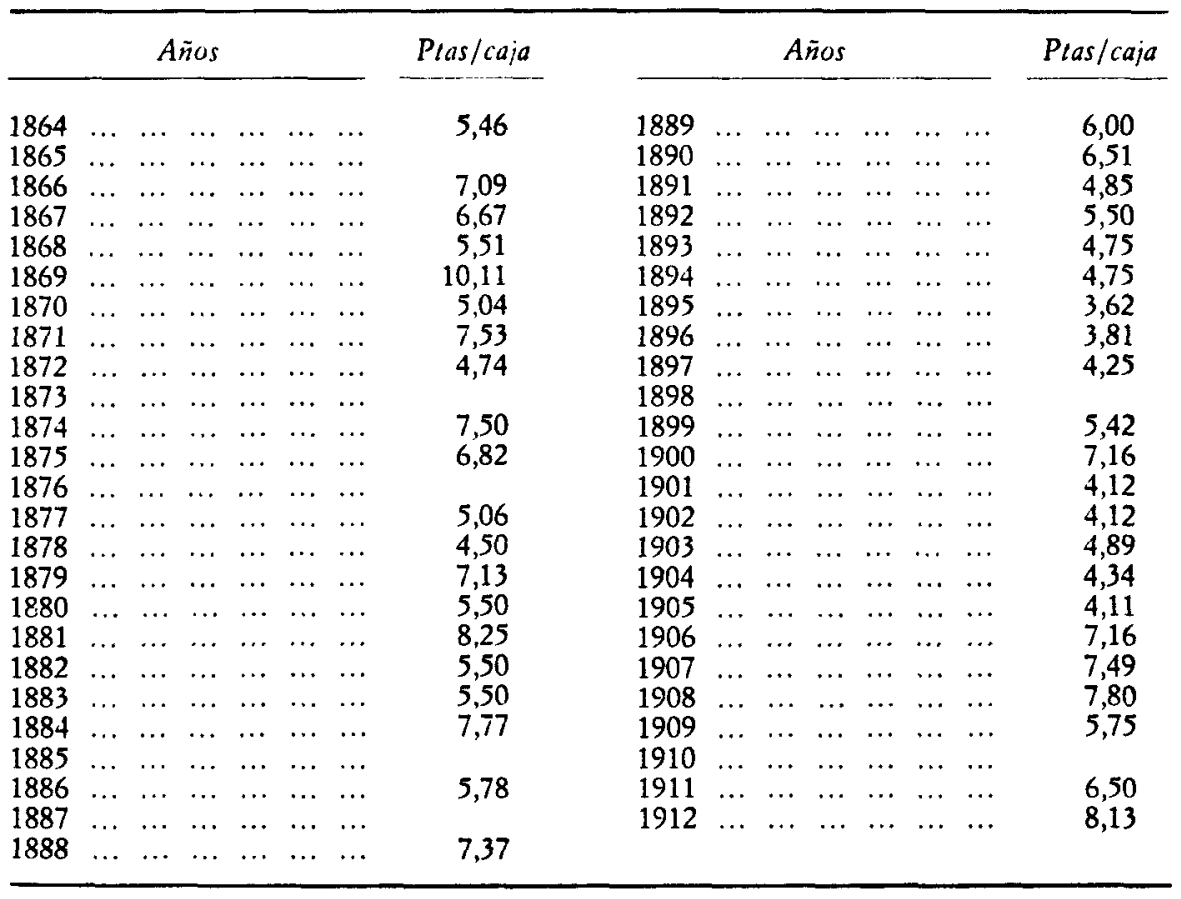

NotA: 1 caja $=11 \mathrm{Kgs}$.

FuenTes: 1864-1897, Avisador Malagueño; 1899-1912, ICB. 


\section{CUADRO 11}

Precios de la uva en Almeria (clase corriente puerto Almería)

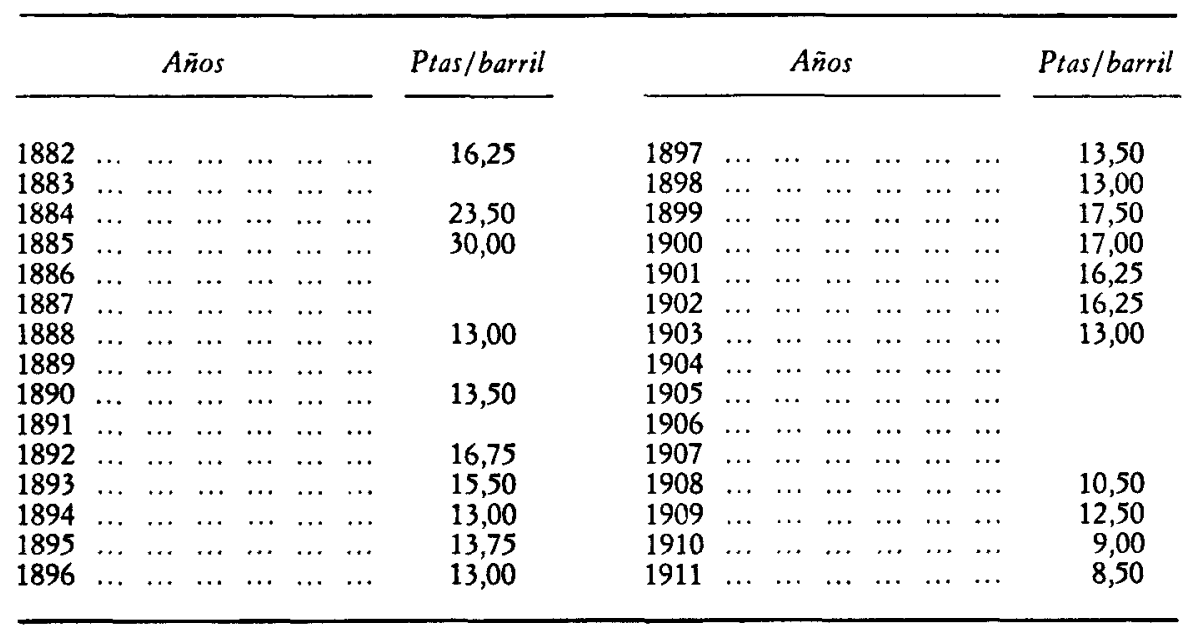

NoTA: 1 barril $=25 \mathrm{Kgs}$.

FUENTES: ICB. 


\section{BIBLIOGRAFIA}

Aguado, Julia (1975): "Las exportaciones de pasas de Málaga durante el siglo XIX", Gibraljaro, núm. 27, pp. 23-41.

Balcells, A. (1980): El problema agrario en Cutaluña. La cuestión rabassaire (1890-1936), Madrid, Servicio de Publicaciones Agrarias.

Bernal, A. M. (1981): «El rebaño hambriento en la tierra feraz», en Historia de Andalucia, tomo VII, dirigida por Domínguez Ortiz, Madrid-Barcelona, Cupsa-Planeta.

- (1985 a): «La llamada crisis finisecular (1872-1919)», en J. L. García Delgado (ed.), La España de la Restauración. Política, economia, legislación y cultura, Madrid, Siglo XXI, pp. 215-263.

- (1985 b): «Economía agraria en la Andalucía contemporáneam, Papeles de Economía Española, núm. 20, pp. 281-297.

Bernal, A. M., y Drain, M. (1975): Les campagnes sevillanes aux $X I X^{c}-X X^{i}$ siècles, Publications de la Casa de Velázquez, serie «Recherches en Sciences Sociales», fasc. II, París, E. de Broccard.

- (1985): "Progreso y crisis de la agricultura andaluza en el siglo XIX», en R. GarraBOU y J. SANZ (eds.), Historia agraria de la España contemporánea. 2. Expansión y crisis (1850-1900), Barcelona, Critica.

Calatayud, S. (1987): "La crisis agraria de finales del siglo xix en Europa», Agricultura y Sociedad, núm. 43, pp. 163-173.

Carnero, M." T. (1980): Expansión vinicola y atraso agrario, 1870-1900, Madrid, Servicio de Publicaciones Agrarias.

- (1985): «Expansión vinícola y retraso agrario (1870-1900)», en R. Garrabou y J. Sanz (eds.), Historia agraria de la España contemporánea. 2. Expansión y crisis (1850-1900), Barcelona, Crítica, pp. 279-300.

Diego García, E., y Solano Sobrado, $M^{*}$ T. (1985): "Algunos efectos de la filoxera en Andalucía: según los Informes de las Comisiones Provinciales al Ministerio de Fomenton, en Actas del II Coloquio de Historia de Andalucia. Historia contemporánea, tomo I, Córdoba, Monte de Piedad y Caja de Ahorros de Córdoba, pp. 121-128.

Gámez Amián, A. (1985): «Estudio de la ganadería en la provincia de Málaga entre 1752 y 1933", en Actas del II Coloquio de Historia de Andalucia. Historia contemporánea, tomo III, Córdoba, Monte de Piedad y Caja de Ahorros de Córdoba, pp. 149.166.

Garrabou, R., y SAnz, J. (1985): “La agricultura española durante el siglo xix: ¿inmovilismo o cambio?», en Historia agraria de la España contemporánea. 2. Expansión y crisis (1850-1900), Barcelona, Crítica, pp. 7-187.

Gómez Mendoza, A. (1983): «Guía para la consulta de los Informes Consulares Británicos sobre España y sus colonias ultramarinas, 1855.1914\%, Moneda y Crédito, núm. 165 , pp. 89-96.

González Portilla, M. (1976): «Acumulación de capital y crisis en el sector agrícola», en J. L. García Delgado, La cuestión agraria en la España contemporánea, Madrid, Cuadernos para el Diálogo, pp. 31-98.

Grupo de Historia Rural (1979): «Contribución al análisis histórico de la ganadería esfañola (1865-1929)", Agricultura y Sociedad, núms. 8 y 10, pp. 129.173 y 105-169.

- (1980): Los precios del trigo y la cebada en España, 1891-1907, Madrid, Servicio de Estudios del Banco de España.

- (1981 a): Los precios del aceite de oliva en España, 1891.1906, Madrid, Servicio de Estudios del Banco de España.

- (1981 b): El vino, 1874-1907. Dificultades para reconstruir la serie de sus cotizaciones, Madrid, Servicio de Estudios del Banco de España.

- (1983): «Notas sobre la producción agraria española, 1891-1931», Revista DE HistoRia ECONómica, núm. 2, pp. 185-252.

- (1985): «Evclución de la superficie cultivada de cereales y leguminosas en España, 1886-1935", en P. Martín Aceña y L. Prados de la Escosura, La Nueva Historia Económica en España, Madrid, Tecnos, pp. 52-70. 
Guisado, J. (1983): "Crisis agraria e invasión filoxérica en la España del siglo XIX", Revista de Historia Económica, núm. 2, pp. 165-184.

Gutiérrez Alvarez, J. S., y Ruiz de Azúa, E. (1985): «Hacia una modernización de la agricultura: el establecimiento de la Colonia de San Pedro de Alcántaram, en Actas del III Coloquio de Historia de Andalucía. Andalucía contemporánea, tomo I, Córdoba, Monte de Piedad y Caja de Ahorros de Córdoba, pp. 67.75.

Herín, F. (1981): Tierra y parentesco en el campo sevillano: La revolución agricola del siglo XIX, Madrid, Servicio de Publicaciones Agrarias.

Iniormes Consularis Británicos (ICB):

- Annual Series: «Diplomatic and Consular Reports on Trade and Finance. Trade of Consular District of Malagas:

Cónsul Mark: (1863).1864 LXI.

Cónsul Wilkinson: (1877).1878-79 LXX.

Cónsul Fins: (1887).1889 LXXX.

Cónsul FinN: (1889).1890-91 LXXXVII.

Cónsul FInN: (1890).1892 LXXXIV.

Cónsul Kimberley: (1893).1894 LXXXVIII.

Córsul Haggard: (1906-07).1908 CXVI.

Cónsul Staniforth: (1912).1913 LXXII.

Vicecónsul de Almería LindSAY: (1893).1894 LXXVIII.

Vicecónsul de Almería LindSAY: (1894).1895 C.

Vicecónsul de Almería Lindsay: (1897).1898 XLVIII.

Vicecónsul de Almería Murison: (1904).1905 CXXVIII.

Vicecónsul de Almcría Murison: (1906).1908 CXVI.

Vicecónsul de Granada Davenhill: (1895).1896 LXXXVIII.

Vicecónsul de Garrucha Ford-Walker: (1904).1905 XCII.

Agente Consular de Adra BenET: (1896).1897 XCIII.

Agentc Consular de Adra Benet: (1911).1912.13 C.

Agente Consular de Motril VII.LAR: (1896).1897 XCIII.

- Informe sobre la plaga del Oidium:

Cónsul de Málaga Mark: 1858 XXX, pp. 208-236.

- Replies to queries from tbe Royal Commission on the Depression of Trade and Industry:

Cónsul de Málaga Bidwell: 1885.

Jiménez Blanco, J. I. (1985): Crisis y expansión de la agricultura de Andalucia Oriental, 1874-1936, Serie Universitaria de la Fundación Juan March, Madrid, Fundación Juan March.

- (1986): La producción agraria de Andalucia Oriental, 1874-1914, 2 vols., Madrid, Servicio de Reprografía de la Universidad Complutense de Madrid.

LAcombı, J. A. (1974): «En Málaga a fines del siglo XIX: Filoxera, desindustrialización y crisis general», Gibrallaro, núm. 26, pp. 91-128

- (1980): «La filoxera en Málaga», Agricultura y Sociedad, núm. 16, pp. 323-370.

- (1986): «La Málaga próspera de Madoz, una realidad fugaz», introducción a la edición facsímil de la parte de Málaga del Diccionario Geográfico-estadistico-bistórico de Pascual Madoz, Valladolid, Ambito Ediciones, pp. VII-XVIII.

- (1987): Crecimicnto y crisis de la cconomia malagucina, Málaga, Servicio de Publicaciones de la Diputación Provincial de Málaga.

Maluquer de Motes, J. (1987): «De la crisis colonial a la Guerra Europea: veinte años de economía española", en J. Nadal, A. Carreras y C. Sudrià (comps.), La economia española en el siglo XX. Una perspectiva bistórica, Barcelona, Ariel, pp. 72-104.

Martín Rodríguez, M. (1982): Azúcar y descolonización. Origen y desénlace de una crisis agraria en la vega de Granada, Granada, Instituto de Desarrollo Regional, Universidad de Granada.

Méndfzz Gonzélez, G., y Sínchez Picón, A. (1985): «El impacto de la Primera Guerra Mundial en la economía almeriense», en Actas del III Coloquio de Historia de Andalucia. Historia contemporánea, tomo III, Córdoba, Monte de Piedad y Caja de Ahorros de Córdoba, pp. 167-178. 
Mignon, Ch. (1982): Campos y campesinos de la Andalucía Mediterránea, Madrid, Servicio de Publicaciones Agrarias.

Moral, J. del (1982): La agricultura española a mediados del siglo XIX, Madrid, Servi cio de Publicaciones Agrarias.

Morilla Critz, J. (1974): "Vid malagueña y vid americana», Gibralfaro, núm. 26, pp. 68.89 .

- (1988 a): «Las condiciones de comercialización de los productos vitícolas y respuesta a la filoxera en Andalucía Oriental (1873-1914)", Revista de Estudios Regionales (en prensa).

- (1988 b): «Una nota sobre la producción agraria de Andalucía Oriental» (comentario a la obra de Jiménez Blanco), REvista de Historia ECoNómiCA, núm. 1, pp. 165-174.

Nadal Farreras, J. (1978): Comercio exterior con Gran Bretaña (1777-1914), Madrid, Instituto de Estudios Fiscales.

NADAL OLLER, J. (1972): "Industrialización y desindustrialización en el sureste español, 1817-1913", Moneda y Crédito, núm. 120, pp. 3-80.

Nadal SánChez, A. (1975): «1890. La huelga de las tejedoras de la industria malagueña», Gibralfaro, núm. 27 , pp. 43-100.

- (1983): Málaga contemporánea: Textos y documentos, Málaga, Instituto de Ciencias de la Educación de Málaga.

Núñez Romero-Balmas, Clara E. (1983): “Catálogo de los Informes Comerciales de los cónsules británicos en Andalucía, 1857-1886», en Anuario de Historia Contemporánea, Granada.

- (1985): El comercio exterior y los problemas de desarrollo económico en Andalucia: 1850-1880, Granada, Instituto de Desarrollo Regional.

NúÑez Romero-Baimas, G. (1983): "Caracteres generales de la economía de exportación del Mediodía almeriense a lo largo del segundo tercio del siglo xix", en III Coloquio de Historia de Andalucia. Historia contemporánea. Cuarta sesión: Industria, comercio, comunicaciones y linanzas, Córdoba, Monte de Piedad y Caja de Ahorros de Córdoba, pp. 1195-1214.

PAlomo, J. (1983): La sociedad malagueña en el siglo XIX, Málaga, Arguval.

Pellejero, C. (1986): "La crisis agraria a firales del siglo xix en Málaga», Revista de Historia Económica, núm. 3, pp. 549.585.

Prqueras, J. (1985): La agricultura valenciana de exportación y su formación bistórica, Madrid, Instituto de Estudios Agrarios, Pesqueros y Alimentarios.

Ruz Márquez, J. L. (1981): Adra. Siglo XIX, Almería, Cajal.

Sínchez-Albornoz, N. (1987): «Los Informes Comerciales de los Cónsules Británicos en España, 1854-1914», Cuadernos de Historia de Espuña, Buenos Aires.

SAnz Fernández, I. (1981): "Notas introductorias al libro de Eduardo de la Sotilla: "Producción y riqueza agrícola de España en el último decenio del siglo Xix y primero del xx"», Agricultura y Sociedad, núm. 18, pp. 303-330.

- (1985 a): «La crisis triguera finisecular: los últimos años», en J. L. Garcí Delga Do (ed.), La España de la Restauración. Politica, economia, legislación y cultura, Madrid, Siglo XXI, pp. 265.310.

- (1985 b): «La historia contemporánea de los montes públicos españoles, 1812-1930. Notas y reflexiones (I)», en R. Garrabou y J. Sanz (eds.), Historia agraria de la España contemporánea. 2. Expansión y crisis (1850-1900), Barcelona, Crítica, pp. 193. 278.

Simpson, I. (1985): «La producción de vino en Jerez de la Frontera, 1850-1900», en P. Martín Aciña y L. Prados de la Escosura (eds.), La Nueva Historia Económica en España, Madrid, Tecnos, pp. 166-191.

VILA, B. (1861): «Descripción de la vendeja», en Guía del viajero en Málaga. Málaga, pp. $283-285$.

Zambrane, J. (1987): Crisis y modernización del olivar español, 1870-1930, Madrid, Mi. nisterio de Agricultura, Pesca y Alimentación. 